Check for updates

Cite this: RSC Adv., 2019, 9, 25712

Received 3rd July 2019

Accepted 12th August 2019

DOI: 10.1039/c9ra05012d

rsc.li/rsc-advances

\section{Electrospun fibers and their application in drug controlled release, biological dressings, tissue repair, and enzyme immobilization}

\author{
Yue Sun, ${ }^{\text {ab }}$ Shihong Cheng, ${ }^{\mathrm{b}}$ Wenjuan Lu, ${ }^{\text {ab }}$ Yanfeng Wang, ${ }^{\text {ab }}$ Pingping Zhang (D) *ab \\ and Qingqiang Yao*ab
}

\begin{abstract}
Electrospinning is a method of preparing microfibers or nanofibers by using an electrostatic force to stretch the electrospinning fluid. Electrospinning has gained considerable attention in many fields due to its ability to produce continuous fibers from a variety of polymers and composites in a simple way. Electrospun nanofibers have many merits such as diverse chemical composition, easily adjustable structure, adjustable diameter, high surface area, high porosity, and good pore connectivity, which give them broad application prospects in the biomedical field. This review systematically introduced the factors influencing electrospinning, the types of electrospun fibers, the types of electrospinning, and the detailed applications of electrospun fibers in controlled drug release, biological dressings, tissue repair and enzyme immobilization fields. The latest progress of using electrospun fibers in these fields was summarized, and the main challenges to be solved in electrospinning technology were put forward.
\end{abstract}

\section{Introduction}

"Electrospinning" evolved from electrospray technology. Electrospray technology refers to the phenomenon that conductive droplets can be jetted at high speed under a high-voltage electrostatic field. Electrospray technology originated from the electrostatic study of droplets by Rayleigh in 1882. Subsequently, research on liquid electrospray was gradually developed. The origin of electrospinning technology began in 1902 when Cooley applied for a patent of spraying liquid devices under an electric field. In 1929, Kiyohito et al. began to manufacture rayon. Formhals described the electrospinning device in a patented form in 1944 .

In the 1930s-80s, the development of electrospinning technology was relatively slow, and its research focused on the development of electrospinning devices. After the 1990s, the Reneker research team in the United States conducted extensive research on the electrospinning process and application. In recent years, with the development of nanotechnology, electrospinning technology has gradually become a research hotspot. The development of electrospinning has gone through four stages: the first stage was mainly to study the spinnability of different polymers, and the influence of process parameters

${ }^{a}$ School of Medicine and Life Sciences, University of Jinan-Shandong Academy of Medical Sciences, Jinan 250062, Shandong, China

${ }^{b}$ Institute of Materia Medica, Shandong Academy of Medical Sciences, Key Laboratory for Biotech-Drugs Ministry of Health, Key Laboratory for Rare \& Uncommon Diseases of Shandong Province, Jinan 250062, Shandong, China. E-mail: pingpingzhang6087@ 163.com; yao_imm@163.com; Fax: +86-0531-82919706; Tel: +86-0531-82919706 and environmental parameters during spinning on fiber diameter and properties. The second stage mainly studied the diversity of nanofiber components and various structures of electrospun fibers. The third stage mainly studied the application of electrospun fibers in the fields of optoelectronics, energy, environment, and biomedicine. The fourth stage mainly studied the large-scale production of electrospun fibers. In the field of biomedicine, the diameter of electrospun nanofibers is smaller than that of cells, which is favorable for mimicking the structure and biological functions of natural extracellular matrices. Most of the human organs and tissues are structurally similar to nanofibers, which is of benefit for the electrospun nanofibers in the repair the human tissues and organs. Electrospun nanofibers have a large specific surface area and porosity, and some electrospun fiber materials have good biocompatibility and degradability, which can be used as drug carriers. Electrospun nanofibers have good application prospects in tissue repair, ${ }^{\mathbf{1 , 2}}$ biological dressing, ${ }^{3,4}$ drug controlled release $^{5-7}$ and enzyme immobilization. Tissue repair is the main research direction in the field of biomedical applications, and electrospun fiber materials were first applied to vascular repair tissue engineering in $1978 .^{8}$ They were then used for bone tissue, ${ }^{9}$ nerve tissue, ${ }^{\mathbf{1 0}}$ tendon tissue, heart valves, urethral stents, skin, and cartilage. In recent years, electrospun nanofibers have been widely used in the pharmaceutical field. ${ }^{11} \mathrm{~A}$ variety of drugs including antibiotics, ${ }^{12}$ proteins,${ }^{13}$ DNA, RNA, growth factors ${ }^{\mathbf{1 4}}$ and anticancer drugs have been loaded into electrospun nanofibers for disease treatment. ${ }^{15-17}$ In recent years, many kinds of enzyme have also been successfully immobilized in fibers by electrospinning. 


\section{Factors influencing electrospinning}

In the process of electrospinning, the polymer solution or fusant is charged and deformed in a high voltage electrostatic field, and a suspended conical droplet is formed at the end of the electrospinning nozzle. ${ }^{18}$ When the charge repulsive force on the surface of the droplet exceeds its surface tension, a stream of polymer droplets (abbreviated as "jet") is ejected at a high velocity. These jets are subjected to high-speed stretching by the electric field force, and then with solvent evaporation and solidification in a short distance, the polymer fibers finally form to be deposited on the collector. The typical electrospinning apparatus is shown Fig. 1, which is composed of a high-voltage power source, a liquid supply device, and a collector. The properties of the polymer solution (such as polymer relative molecular mass, solution concentration and viscosity, surface tension, conductivity), the process parameters (such as applied voltage, solution flow rate, fiber receiving distance), and the environmental parameters (such as ambient temperature and humidity) have an effect on the morphology of the fiber during electrospinning (Table 1).

\subsection{Properties of polymer solutions}

2.1.1. Relative molecular mass. Relative molecular mass of the polymer is an important parameter affecting electrospinning, because it directly affects the rheological and electrical properties of the electrospinning solution. The fibers could only be prepared by electrospinning when the polymer relative molecular mass reaches a certain value. The polymers in low molecular mass tends to form beads during the electrospinning process, while increasing the molecular mass of polymers can reduce the number of beads and form fibers with uniform diameter. The morphological change was studied to demonstrate the effect of the molecular mass on the polyethylene glycol oxide (PEO) electrospinning fibers. The PEO electrospinning solutions with different molecular mass (various viscosity average molecular weights of 100000 (P1),

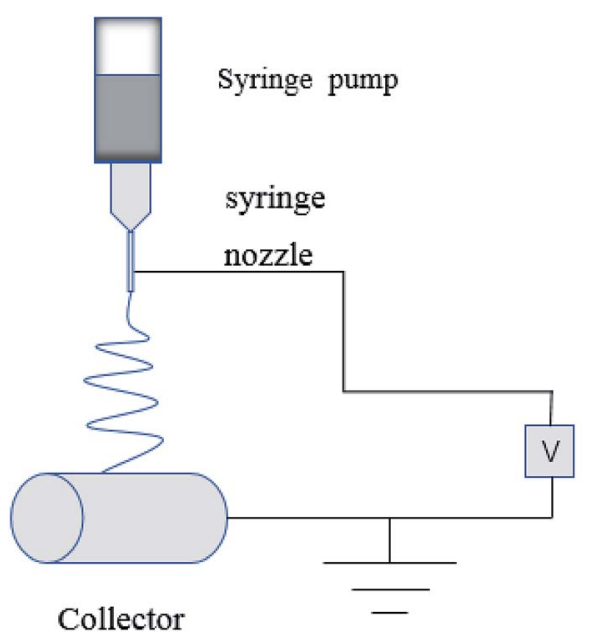

High voltage

Fig. 1 Typical electrospinning apparatus.
200000 (P2) and 400000 (P3)) had different electrospun jet shapes, and the change in the jet shape consequently caused the difference in the deposition formation. The P1 showed an agglomerated formation, and P2 revealed a mixed formation with particles, beads, and fibers, while complete nanofibers are produced with $\mathrm{P} 4 .{ }^{19}$ Wang et al. also found that the larger the molecular mass of polystyrene (PBS), the larger the fiber diameter. ${ }^{20}$

2.1.2. Viscosity. The entanglement of polymer molecular chains in solution causes the solution to reach a certain viscosity, which is a necessary condition for the preparation of fibers by electrospinning. The greater the relative molecular mass of the polymer, the longer the molecular length, which is favorable for the polymer molecular chain to entangle in solution, and the greater the viscosity of the solution. When the relative molecular mass of the polymer is determined, the concentration of the solution becomes an important factor affecting the entanglement of the polymer molecular chain in the solution. As the concentration of the polymer solution increases, the viscosity of the solution will increase. Nanofibers can be formed by controlling the viscosity of the polymer solution in a certain optimal range during electrospinning. The viscosity of the polymer solution has an effect on the morphology of the electrospun fibers. The effect of the viscosity of the PEO solution on the morphology of microspheres in electrospun nanoparticles was studied by Fong et al. The results showed that the diameter of microspheres increased and the density of microspheres decreased with an increase of solution viscosity, while under the condition of high viscosity, the microspheres becomes spindle-shaped, and then nanofibers are formed. An increase in viscosity of the solution is helpful for the formation of smooth nanofibers. ${ }^{21}$

2.1.3. Surface tension. The surface tension of the solution is an important factor affecting electrospinning. In the electrospinning process, the electrostatic repellent force on the surface of the charged polymer solution or the fusant must be greater than its surface tension. Bhardwaj et al. studied the effect of surface tension on the morphology of nanofibers. ${ }^{22}$ The results showed that increasing the concentration of the electrospinning solution can reduce the surface tension of the solution to a certain extent, which is beneficial for forming continuous and uniform fibers. When the concentration of the solution is constant, the surface tension of the solution can be adjusted by changing the composition of the solvent or by adding a surfactant to the solution.

2.1.4. Conductivity. The conductivity of a polymer solution is related to the electrification ability of the polymer solution. The conductivity of a polymer solution increases with an increase of its carried electric quantity, and the conductivity directly affects the morphology of electrospun fibers. The effects of solution properties of polystyrene (PS), polyacrylonitrile (PAN), polyhydroxybutyrate (PHB), poly D-L-lactic acid (PDLA), and nylon 6 on electrospun fibers were studied by Chi-wang et al. It was found that the conductivity of the five-polymer solution is the main factor affecting electrospinning. The conductivity of the solution can be changed by adding salt or 
Table 1 Effect of the main electrospinning parameters on fiber diameter and morphology

\begin{tabular}{|c|c|c|c|c|c|c|c|c|c|}
\hline & \multicolumn{4}{|c|}{ Polymer solution properties } & \multicolumn{3}{|c|}{ Process parameters } & \multicolumn{2}{|c|}{ Environmental parameters } \\
\hline & $\begin{array}{l}\text { Relative } \\
\text { molecular } \\
\text { mass } \uparrow\end{array}$ & $\begin{array}{l}\text { Concentration } \\
\text { and viscosity } \uparrow\end{array}$ & $\begin{array}{l}\text { Surface tension } \\
\uparrow\end{array}$ & $\begin{array}{l}\text { Conductivity } \\
\uparrow\end{array}$ & Voltage $\uparrow$ & Flow rate $\uparrow$ & $\begin{array}{l}\text { Receiving } \\
\text { distance } \\
\uparrow\end{array}$ & Temperature $\uparrow$ & Humidity $\uparrow$ \\
\hline $\begin{array}{l}\text { Fiber } \\
\text { diameter }\end{array}$ & $\uparrow$ & $\uparrow$ & $\uparrow$ & $\downarrow$ & $\downarrow$ Then $\uparrow$ & $\uparrow$ & $\downarrow$ & $\downarrow$ & \\
\hline $\begin{array}{l}\text { Fiber } \\
\text { morphology }\end{array}$ & $\begin{array}{l}\text { Less } \\
\text { beads, } \\
\text { uniform } \\
\text { fibers }\end{array}$ & $\begin{array}{l}\text { High viscosity, } \\
\text { no continuous } \\
\text { fiber }\end{array}$ & $\begin{array}{l}\text { Increased } \\
\text { probability of } \\
\text { generating } \\
\text { beaded } \\
\text { structures }\end{array}$ & $\begin{array}{l}\text { Wide fiber } \\
\text { diameter } \\
\text { distribution }\end{array}$ & $\begin{array}{l}\text { The fiber } \\
\text { diameter } \\
\text { distribution is } \\
\text { widened, } \\
\text { which is not } \\
\text { conducive to } \\
\text { obtaining } \\
\text { a fiber with } \\
\text { a smooth } \\
\text { surface, and } \\
\text { a bead } \\
\text { structure is } \\
\text { generated at } \\
\text { a high voltage }\end{array}$ & $\begin{array}{l}\text { Excessive flow } \\
\text { rate resulting } \\
\text { in beaded } \\
\text { fibers }\end{array}$ & & $\begin{array}{l}\text { More uniform } \\
\text { fiber diameter } \\
\text { distribution }\end{array}$ & $\begin{array}{l}\text { Forming } \\
\text { a multiporous } \\
\text { structure on } \\
\text { the surface of } \\
\text { the fiber }\end{array}$ \\
\hline
\end{tabular}

polyelectrolyte, or changing the solvent composition, and thereby the morphology of fiber can be changed. ${ }^{23}$

2.1.5. Solvents property. The properties of solvents, such as conductivity, volatility and the solubility of solvent to polymers will affect the electrospinning process, and then affect the morphology of electrospun fibers. The diameter of the electrospinning fiber decreases with the increase of the conductivity of solvent. The spinning nozzle is easy to be blocked when solvent volatility is too fast, while prepared fibers tends to adhere when solvent volatilization is too slow. The volatility of solvents also affects the morphology and structure of fibers, such as surface roughness, porous structure, flat diameter. The solubility of solvent to polymer affects the viscosity and surface tension of electrospinning solution, thus affecting their spinnability. The suitable electrospinning solvent should have good volatility, appropriate solubility to polymers, suitable vapor pressure and boiling point. In the spinning process, the blending solvents strategy is always adopted to adjust the properties of the electrospinning solutions, so as to adjust the electrospun fiber structures. Lagaron studied the effect of solvent selection on the electrospinnability and morphology of polyimide fibers. The dimethyl sulfoxide (DMSO)/ $N, N$-dimethylformamide (DMF) and $N, N$-dimethylacetamide (DMAC)/DMF solutions showed poor electrospinnability because of the high volatility of DMF and high solubility parameters values of the polymer. Both factors produced clogged nozzle and interrupted the continuity electrospinning. The defect-free PI nanofibers can be obtained by using four selected blending solvents (DMF/N-methyl-2pyrrolidone (NMP), DMSO/NMP, DMAC/DMSO, DMAC/NMP) during a continuous electrospinning process. ${ }^{24}$

2.1.6. The temperature of the polymer solution. The temperature of polymer solution not only affects the viscosity and surface tension of the electrospinning solution, but also affects the volatilization of solvent in electrospinning process.
The viscosity and surface tension of electrospinning solution decrease with the increase of the polymer solution temperature. Under the same applied electric field, the solvent evaporates rapidly and solidifies into uniform fibers. Temperature may have two opposite effects on resulting fiber diameter. Firstly, rapid solvent volatilization shortens the stretch distance of electrospinning droplet which resulting in larger fiber diameters, on the other hand, viscosity and surface tension decrease at higher temperatures, resulting in thinner fibers. ${ }^{25}$

\subsection{Process parameters}

2.2.1. Applied voltage. In the process of electrospinning, the voltage applied to the polymer fluid must exceed a certain critical value, while the resulting electrostatic repulsive force is sufficient to overcome its surface tension, resulting in a microjet that forms fibers. The diameters of the resulting fibers are smaller at higher voltages, but the number of beads in the fiber membrane is greater. In addition, a change of voltage directly affects the stretching of the jet, which affects the orientation of the molecular chain and ultimately affects the crystallinity of the fiber. Therefore, the magnitude of the voltage has a great influence on the morphology and structure of the fiber. ${ }^{26}$ The type of voltage (direct current (DC) or alternating voltage (AC)) also effects electrospinning. ${ }^{27}$ It was found that when a DC high voltage power supply is used, shaking of the charged jet makes it unstable, and it is difficult to deposit the resulting fiber on the receiving device. When an AC electric field is used in the electrospinning process, the shaking instability of the charged jet is reduced, and the diameter of the obtained fibers is also reduced..$^{28}$

2.2.2. Solution flow rate. The flow rate of the electrospun solution is also an important electrospinning process parameter as it greatly influences the fiber shape. The solution flow rate determines the amount of spinnable solution in the 
electrospinning process. A low flow rate is beneficial for the evaporation of the solvent, which will accelerate the material transfer rate. However, Taylor pointed out that the Taylor cone shape cannot be maintained if the flow rate of the electrospinning solution is too low to replace the solution ejected from the tip of the capillary as the fiber jet. ${ }^{29}$ When the voltage is constant, the diameter of the jet will increase with an increase of the solution flow rate, and the resulting fiber diameter will also increase. ${ }^{30}$ When the concentration of the electrospinning solution is large, fibers with pronounced beaded morphologies are obtained because of the incompletely drying of fibers before reaching the collector. ${ }^{22}$

2.2.3. Fiber receiving distance. The distance between the syringe nozzle and the collector affects the degree of volatilization of the solvent, which controls the size and the morphology of the electrospun fibers. The solvent can be sufficiently volatilized when the receiving distance is increased to a certain extent, while electrospun fibers with smaller diameters can be obtained. On the other hand, the electric field strength will be reduced with an increasing receiving distance, which will lead to a decrease of the jet velocity, a weaker tensile action, leading to an increase in the diameter of the fibers. ${ }^{31} \mathrm{An}$ appropriate distance is required for the drying of the fibers before reaching the collector. If the distance is too close or too far, fibers with beads are obtained. ${ }^{32}$ Buchko found that the morphology of electrospun fibers changed from flat to round shape when the distance between the syringe nozzle and the collector varied from $0.5 \mathrm{~cm}$ to $2 \mathrm{~cm}^{33}$

2.2.4. Receiving device. The receiving device shows a signification on the properties of electric field, which in turn affects the distribution and structure of electrospinning nanofibers. $^{34}$ The randomly arranged fibers, patterned fibers, ordered fibers and three-dimensional structural fibers can be obtained using different receiving devices. Randomly oriented fibers generally formed when using a grounded solid collector (Fig. 2A) (e.g., aluminum foil) as the receiving device. ${ }^{35}$ The guide wires with different topographies structures were selected

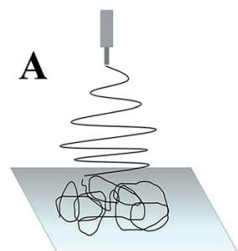

B

C

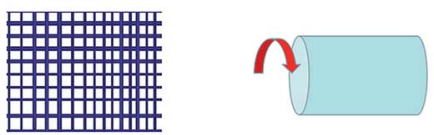

- solid collector • guide wires collector • rotating mandrel
D

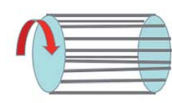

-rotating wire drum
$\mathbf{E}$

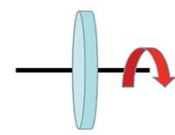

- rotating disk

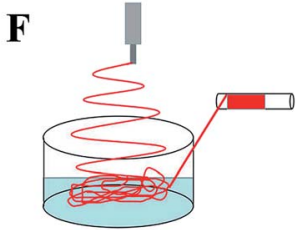

- liquid bath collector
Fig. 2 Electrospinning receiving devices: (A) solid collector, (B) guide wire collector, (C) rotating mandrel, (D) rotating wire drum, (E) rotating disk, (F) liquid bath collector. as the receiving device to construct electrospinning nanofibers with different patterns (Fig. 2B). ${ }^{36}$ The ordered nanofibers in the arrangement direction can be obtained by adjusting the rotation speed of the rotating collector (such as rotating mandrel (Fig. 2C), rotating wire drum (Fig. 2D), rotating disk (Fig. 2E)). ${ }^{37}$ Special three-dimensional electrospun fiber yarns can be obtained by using water or ethanol coagulation bath to receive electrospun fibers, which are solidified in liquid bath and then collected by rollers (Fig. 2F). ${ }^{38,39}$ Through the selection and improvement of the receiving device, the morphology of electrospinning fibers can be controlled.

\subsection{Environmental parameters}

2.3.1. Temperature. The movement of the solution molecules accelerates with an increase of the ambient temperature, which improves the conductivity of the solution. Some proteins and ionic polysaccharides have gel and electrolyte properties, and a temperature rise can lower the viscosity of these solutions. In addition, the evaporation rate of the solvent accelerates with an increase of the ambient temperature. All these effects result in a decrease in the electrospun fiber diameter. ${ }^{40}$

2.3.2. Humidity. The change of environmental humidity not only affects the volatility of the solvent, but also causes a change of the fiber surface morphology. When hydrophobic polymers are dissolved in organic solvents, a high relative humidity leads to the formation of porous nanofibers. Moreover, the number and size of the pores vary with the humidity. ${ }^{41}$

2.3.3. Air pressure. In the process of electrospinning, air pressure will affect the volatilization of solvent, which affected the fiber diameter and the precision of the fiber deposition. The fibers with good consistency can be obtained by electrospinning in a closed environment with pressure, but when many layers of fibers were deposited, the heat generated by the motor will become an issue. ${ }^{42}$ Moreover, the instability of the air pressure will also lead to the instability of the jet, which would float up and down. At present, the electrospinning process is basically carried out under atmospheric pressure.

The effects of polymer solution properties, process parameters, and environmental parameters on the morphology of electrospun fibers do not exist in isolation. In the process of electrospinning, various factors need to be considered.

\section{Electrospun fiber types}

A variety of nanofibers can be prepared by selecting different spinning materials, including inorganic nanofibers, organic nanofibers, and inorganic/organic nanofibers. ${ }^{43,44}$ In the fields of pharmacy and biomedicine, organic nanofibers and inorganic/organic nanofibers are widely used in drug controlled release, biological dressings, tissue repair and enzyme immobilization fields. ${ }^{45-50}$

\subsection{Inorganic nanofibers}

Inorganic nanofibers are widely used in catalysis, electrode materials, electronic engineering, sensing and other fields. Because of its poor mechanical properties, the application of 
inorganic/organic composite nanofibers is more common in the field of biomedicine, and the application of electrospun inorganic nanofibers is relatively limited. Zhang prepared $\mathrm{TiO}_{2}$ nanofiber-coated Si substrates with removing organic components from $\mathrm{PVP}-\mathrm{TiO}_{2}$ electrospun nanofibers/Si substrates by calcination at $400{ }^{\circ} \mathrm{C}$. The results showed that the geometric orientation of $\mathrm{TiO}_{2}$ nanofibers could approve simulate extra cellular matrix (ECM) better than Si substrates, thus improving the affinity between cells and substrate, which greatly improved the ability to capture cancer cells. ${ }^{51}$ Liu prepared a cancer cell capture/release microchip based on the $\mathrm{MnO}_{2}$ electrospinning nanofibers. The $\mathrm{MnO}_{2}$ nanofiber which mimiced the ECM could lead to high cancer cell capture ability. ${ }^{52}$ The $\mathrm{NaYF}_{4}: \mathrm{Yb}^{3+}$, $\mathrm{Er}^{3+} @ \mathrm{SiO}_{2}$ core-shell nanofibers were prepared by electrospinning followed with reoxidation process. The prepared $\mathrm{NaYF}_{4}: \mathrm{Yb}^{3+}, \mathrm{Er}^{3+} @ \mathrm{SiO}_{2}$ nanofibers had the ability to simultaneously monitor dual drug delivery (ibuprofen and doxorubicin) with high sensitivity and a broad detection range. ${ }^{53}$

\subsection{Organic nanofibers}

3.2.1. Natural polymer nanofibers. The natural polymers of animal sources include collagen, chitosan, chitin, and gelatin, and the natural polymers of plant sources include sodium alginate, plant protein, cellulose, lignin, natural rubber, and starch. The natural polymers of microbial sources include hyaluronic acid. As a renewable resource, natural polymers generally have good biocompatibility and degradability. They are environmentally friendly green polymer materials and have a wide range of applications in the field of biomedicine. Jiang et al. dissolved collagen in a low corrosive, mild ethanolaqueous solution, with citric acid used as the crosslinker and glycerol as the chain extender. Microcollagen fibers with good cell compatibility and aqueous solution stability were prepared by electrospinning using this system. ${ }^{54}$ Chouhan et al. prepared silk fibroin (SF) nanofibers loaded with the epidermal growth factor (EGF) and ciprofloxacin hydrochloride by electrospinning which could be used for wound dressings. ${ }^{55}$ Chitosan electrospun nanofiber membranes loaded with henna extract were prepared by Yousefi et al. Cellular experiments showed that the fiber membrane could be used as an antibacterial wound healing dressing. ${ }^{56}$ Marcolin prepared silk fibroin-gelatin (SF/ gel) composite fibers through electrospinning, and the prepared fibers had good biocompatibility and mechanical properties, which could be used as a small diameter vascular regeneration scaffold. ${ }^{57}$ Vicini et al. invented a method for preparing alginic acid and alginic acid/hyaluronic acid fiber membranes by wet electrospinning. Water was used instead of a toxic solvent in the wet process, and crosslinked alginate was obtained..$^{58}$ Lu used corn protein and hydrophobic ethyl cellulose as raw materials, and synthesized composite electrospinning nanofibers loaded with indomethacin. The results of a dissolution experiment in vitro showed that the composite nanofibers could control the release of indomethacin. ${ }^{59}$ Biocompatible hyaluronic acid nano-fiber scaffolds were obtained by electrospinning, using water as the green solvent, and polyvinyl alcohol (PVA) as the carrier of the hyaluronic acid polymer. Hydroxypropyl- $\beta$-cyclodextrin was also added to the electrospinning process to stabilize the electrospinning process and ensure the uniformity of the obtained nanofibers. The drug release properties of the non-steroidal anti-inflammatory drug naproxen (NAP) loaded on the above fiber scaffold were studied. The results showed that hydroxypropyl- $\beta$-cyclodextrin paved the way for wound dressing applications with controlled drug encapsulation-release properties. ${ }^{60}$

3.2.2. Synthetic polymer nanofibers. Synthetic polymers are the most widely used electrospinning materials at present. As long as solvents can be found or can be converted from soluble precursors, synthetic polymer electrospun fibers can be obtained by solution electrospinning (Table 2).

Electrospun multi-component synthetic polymer solutions can obtain multi-component synthetic polymer nanofibers to achieve a composite of different polymer properties. The mechanical strength, biological activity, and degradability of the fibers can also be regulated by adjusting the proportion of each component. Such as: PVP/PLA, polyaniline/PS, PLA/PLGA, $\mathrm{PVC} / \mathrm{PU}$, and polyaniline/PA electrospun nanofibers. Elakkiya prepared curcumin loaded PLA/PVA composite nanofiber membranes by the electrospinning method. The composite fiber membrane had good biocompatibility. The release ratio of curcumin in PLLA/PVA composite fiber membranes was about $78 \%$ within 4 days. It has good potential in the field of biocompatible scaffolds. ${ }^{64}$

3.2.3. Blended fibers. Some natural polymers themselves are difficult to electrospin, but electrospinning nanofibers can be obtained by composite spinning with a better spinnable synthetic polymer, such as chitosan/PLA, PLGA/chitin, collagen/ PLA, and glucan/PLGA fiber. These fibers can be used for controlled release of biomedical and bioactive molecules. Basha blended $\beta$-1,3-glucan with polyvinyl alcohol (PVA) to obtain composite electrospinning nanofibers with diameters less than $100 \mathrm{~nm}$. The fibers have good hydrophilicity, good biodegradability (10\% degradation for 14 days) and a good swelling property (about 170\%). ${ }^{65}$ Salicylic acid loaded PCL-shellac composite electrospun nanofibers were fabricated by Ma. By adjusting the ratio of shellac to PCL, drug-loaded fiber membranes with good tensile strength and drug release performance could be obtained. ${ }^{66}$ Chakrapani et al. used PCL and collagen extracted from bovine skin mixed in different proportions, with acetic acid as the solvent, and then electrospun them to obtain a nanofiber membrane with a porosity of $60 \%$ and a fiber diameter of 100-200 nm. Compared with electrospun collagen nanofibers with hexafluoroisopropanol (HFIP) as the solvent, collagen electrospun nanofibers obtained from the acetic acid solvent system can be safely used in wound repair in skin tissue engineering. ${ }^{67}$

\subsection{Inorganic/organic nanofibers}

Inorganic/organic composite nanomaterials are research hotspots in the field of composite materials. Electrospinning technology is one of the effective methods for preparing inorganic/organic composite nanomaterials. ${ }^{68}$ The main way to prepare inorganic/organic electrospun composite nanofibers is 
Table 2 Some synthetic polymer nanofibers and their applications

\begin{tabular}{|c|c|c|c|c|}
\hline Synthetic polymer & Solvent & Degradability & Application & Reference \\
\hline Polylactic acid (PLA) & Chloroform $\left(\mathrm{CHCl}_{3}\right)$ & $\checkmark$ & $\begin{array}{l}\text { Loading sodium dichloro- } \\
\text { acetate (DCA) could inhibit } \\
\text { cervical cancer in vivo the } \\
\text { deterioration of cervical } \\
\text { cancer in vivo }\end{array}$ & 47 \\
\hline Polycaprolactone (PCL) & $\begin{array}{l}\text { Hexafluoroisopropanol } \\
\text { (HFIP) }\end{array}$ & $\checkmark$ & $\begin{array}{l}\text { Loading paclitaxel, } \\
\text { treatment of liver cancer }\end{array}$ & 61 \\
\hline Polyurethane (PU) & HFIP & $x$ & $\begin{array}{l}\text { Electrospun fiber scaffold } \\
\text { for cell attachment and } \\
\text { proliferation }\end{array}$ & 63 \\
\hline
\end{tabular}

by adding inorganic oxides $\left(\mathrm{TiO}_{2},{ }^{69} \mathrm{SiO}_{2},{ }^{70} \mathrm{ZnO},{ }^{71}\right.$ and $\mathrm{Fe}_{3} \mathrm{O}_{4}$ (ref. 72)), graphene (GO),${ }^{73}$ metals $\left(\mathrm{Ag},{ }^{74} \mathrm{Pt},{ }^{75} \mathrm{Au},{ }^{76} \mathrm{Cu},{ }^{77}\right.$ and $\mathrm{Fe}^{78}$ ), carbon nanotubes $(\mathrm{CNT})^{79}$ and other nanomaterials to polymer fibers. The specific preparation methods are as follows: (1) dispersive mixed electrospinning: inorganic nanomaterials are directly dispersed in a polymer solution and then electrospun. (2) In situ composite electrospinning: in situ synthesis of inorganic nanomaterials are electrospun in order to embed inorganic materials in organic fibers. (3) Sol-gel electrospinning: the precursor sol of inorganic nanomaterials is mixed in the polymer solution for electrospinning. (4) Post-treatment of electrospun fibers: such as UV reduction, gas-solid reaction, liquid phase deposition, and the chemical vapor process. An inorganic/organic composite nanofiber can be obtained after the post-treatment. The inorganic materials commonly used in the biomedical field are $\mathrm{TiO}_{2},{ }^{69} \mathrm{SiO}_{2},{ }^{70} \mathrm{GO},{ }^{73} \mathrm{Ag},{ }^{74} \mathrm{Pt},{ }^{75}$ and $\mathrm{Au} .{ }^{76}$

Blantocas prepared high-efficiency antibacterial $\mathrm{TiO}_{2} /$ chitosan fiber material by chemical vapor depositing titanium dioxide particles onto electrospun chitosan fibers. The antibacterial effect of the material on Staphylococcus aureus was achieved by the photocatalytic activity of $\mathrm{TiO}_{2} . \mathrm{TiO}_{2}$ can generate high activity free radicals, which can fully destroy microbes and produce antibacterial effects. ${ }^{69}$ Song fabricated a dual-drug loaded $\mathrm{PLGA} / \mathrm{SiO}_{2}$ microsphere electrospun composite fiber. The drug in the PLGA matrix was rapidly released, while the drug in the $\mathrm{SiO}_{2}$ microsphere was slowly released. The on-demand release of the two drugs in the composite fiber can be realized through ultrasonic irradiation. ${ }^{70}$ Mao synthesized drug-loaded PLA/GO nanofiber membranes by electrospinning. The addition of GO significantly improved the thermal stability and mechanical properties of the nanofiber membranes, and increased the cumulative release of drugs. ${ }^{73}$ Shalumon prepared electrospun fibers with a core-shell structure of PEG/PCL/Ag (PPA) as the shell and hyaluronic acid (HA)/ ibuprofen as the core. $\mathrm{Ag}$ nanoparticles and ibuprofen have anti-infection and anti-inflammatory effects, respectively. The antibacterial effect of core-shell fibers on Gram-negative bacteria and Gram-positive bacteria was shown to be related to the $\mathrm{Ag}$ nanoparticles in the electrospun fibers. ${ }^{74}$ Aggarwal synthesized cisplatin-loaded PCL/chitosan electrospun composite nanofibers for the chemotherapy of cervical cancer in mice. The composite nanofibers can maintain the sustained release of the drug within a month. In vivo studies showed that the composite nanofibers have better anti-tumor effects on the 14th and 21st days after treatment. ${ }^{75}$ The anticancer drug temozolomide (TMZ) loaded polycaprolactone-based polyurethane/Au composite nanofibers were obtained by Irani using electrospinning. Studies showed that gold particles coated on the outer surface of the composite fiber can enhance the anti-tumor activity of the drug-loaded fiber on glioblastoma. ${ }^{76}$ Gao first inserted the non-steroidal anti-inflammatory drugs ibuprofen or ketoprofen into layered double hydroxide $(\mathrm{LDH})$ nanoparticles to obtain a drug-LDH composite, and then added the drug-LDH composite to the PCL solution to form an electrospinning stock solution, finally it was electrospun to obtain organic-inorganic nanofiber materials. A drug release test in vitro showed that the release rate of ibuprofen or ketoprofen was slow in PCL fibers loaded with drug-LDH. After 5 days, only $44-48 \%$ of ibuprofen was released, while the release of ketoprofen was 20-25\%. All drugs-LDH/PCL composite fibers could release the drug after 5 days. This composite fiber can be used as an implantable drug delivery system. ${ }^{80}$ Oliveira fabricated calcium phosphate ceramic particle loaded hydroxypropyl methylcellulose (HPMC) electrospun fibers, which can be used as an injectable composite material. The fiber can more persistently release calcium. In a rat bone defect model, the fiber could regulate the release of calcium, which can accelerate bone formation and increase the number of generated blood vessels. ${ }^{81}$

\section{Types of electrospinning}

Uniaxial electrospinning and coaxial electrospinning are often used to load drugs into fibers. ${ }^{\mathbf{8 2} 83}$ The preparation of drugloaded fibers by uniaxial electrospinning includes two methods: (1) simple blending electrospinning: electrospinning after the drug is dissolved in the polymer solution using a single nozzle, and the drug is embedded in the polymer matrix (Fig. 3A), and (2) after the polymer fiber is obtained by uniaxial electrospinning, the polymer fiber is modified on the surface. Drugs are loaded on the surface of modified fibers through electrostatic interaction, hydrophobic interaction, hydrogen 


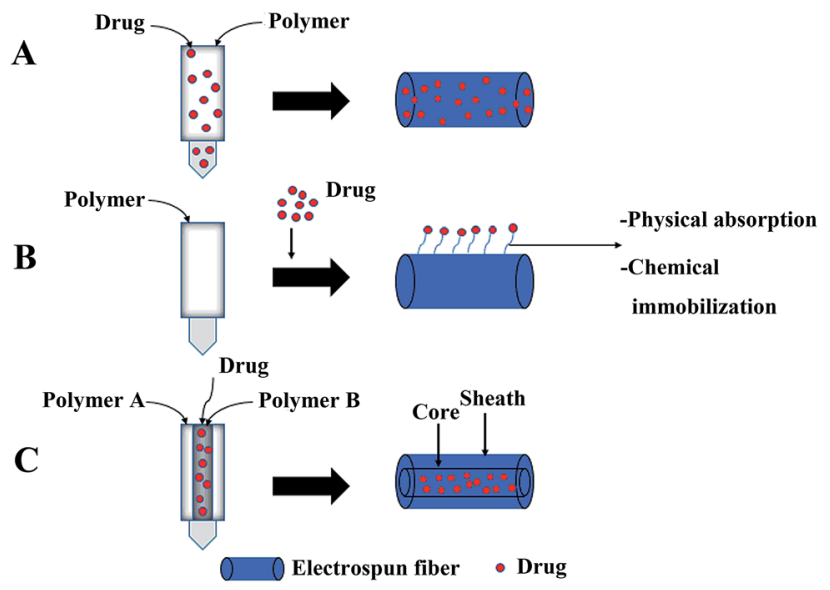

Fig. 3 Three main forms of drugs in drug-loaded electrospinning fibers: (A) drugs embedded in the carrier polymer, (B) drugs on the surface of fibers, and $(C)$ drugs packaged in the core layer of the fibers.

bond interaction, and van der Waals interaction (Fig. 3B). Among them, the simple blending electrospinning method is the main method of uniaxial electrospinning to obtain drugloaded fibers. The drug in drug-loaded coaxial electrospun fibers is packaged in the core layer of the fiber (Fig. 3C). ${ }^{84}$

\subsection{Simple blending electrospinning}

The simple blending electrospinning to prepare drug-loaded fiber is to dissolve the drug in one or more polymer spinning solution, and then use a single nozzle to electrospin. The operation is simple and since a multi-component composite can be realized, so it is widely used. Simple blending electrospinning can encapsulate hydrophilic and lipophilic drugs as well as biomolecules (such as RNA, DNA, and proteins) into the fiber. The drugs in simple blend drug-loaded fibers are mainly released through simple surface diffusion and pores caused by the degradation of the fiber (Fig. 4A). A variety of drug-loaded fibers were prepared using simple blending electrospinning, such as antibiotics, ${ }^{85}$ cytostatic drugs,${ }^{86,87}$ and antiinflammatory analgesics loaded fibers. ${ }^{88}$ However, simple

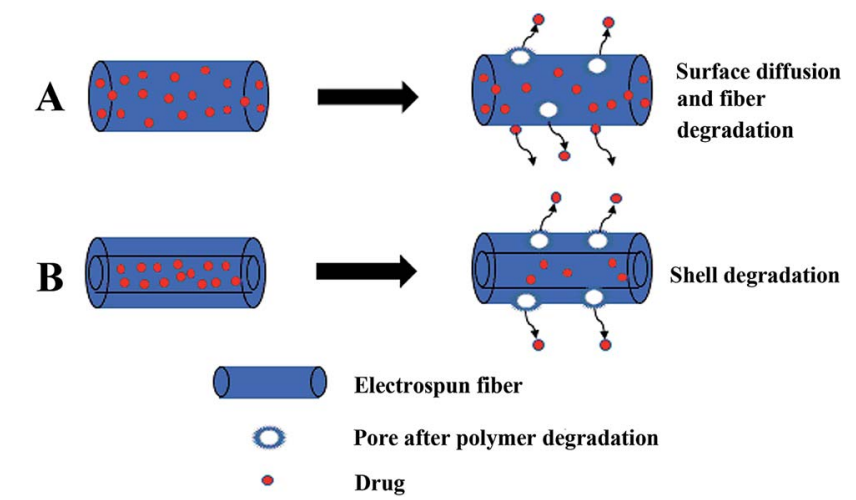

Fig. 4 Illustration of the release of drugs from electrospun fibers. (A) Drugs released through simple surface diffusion and pores caused by the degradation of the fiber, (B) drugs in the core-shell structure drugloaded fiber are released depending on the degradation of the shell layer. blending electrospinning has many shortcomings in drug delivery: sensitive drug molecules, proteins, and DNA are often denatured and lose their biological activity in the organic solvents used in simple blending electrospinning, the encapsulation efficiency of the prepared fiber is low, the distribution of drugs in the fibers is uneven, and the sudden release of drug is obvious.

\subsection{Coaxial electrospinning}

Coaxial electrospinning is used to prepare the core layer solution and the shell layer solution, and then they are electrospun with a coaxial nozzle to form a coaxial jet to produce core-shell structure fibers (Fig. 5). Drugs are loaded on the core layer of the fiber by coaxial electrospinning. The double-layer shielding effect established by the special core-shell structure of coaxial electrospun fibers can effectively solve the drug sudden release problem. Sometimes the drug can also be loaded on the shell layer. The load of multicomponent drugs and the controlled release of drugs can be realized. The release of drugs from drugloaded coaxial electrospun fibers depends on the degradation of the shell layer, as shown in Fig. 4B. De Souza prepared degradable drug-loaded core-shell nanofibers by coaxial electrospinning, with PVA and bevacizumab as the core, and PCL and gelatin as the shell. ${ }^{89}$ Sakib reported the continuous nanoscale encapsulation of 5-fluorouracil (FU) and paclitaxel into biocompatible PCL nanofibers using a coaxial electrospinning process. The drug-loaded core-shell fibers had a better therapeutic effect on breast cancer than the use of the anticancer drug alone. ${ }^{90}$ Coaxial electrospinning is widely used in biomedical fields such as drug release, tissue engineering, and drug-loaded medical dressings (Table 3).

\subsection{Other types}

There are many other types of electrospinning used to produce nanofiber materials with various functions, such as emulsion electrospinning, near-field electrospinning, multi-needle

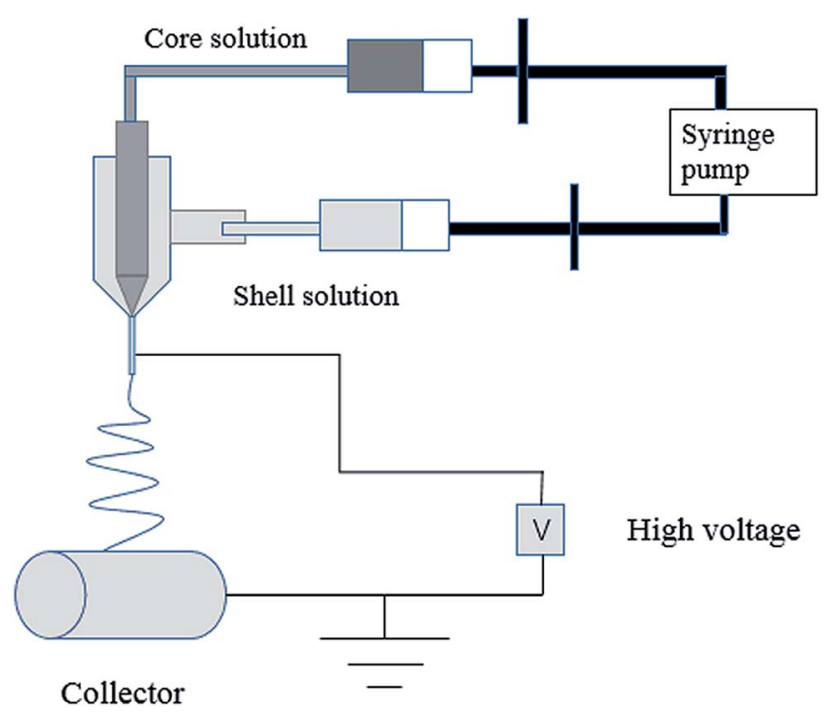

Fig. 5 Schematic diagram of a coaxial electrospinning device. 
Table 3 Coaxial electrospun nanofibers and their applications

\begin{tabular}{|c|c|c|c|}
\hline Shell & Core layer & Use & Reference \\
\hline Cellulose acetate & PCL & Loaded with nisin for antibacterial & 112 \\
\hline PCL/gelatin & PVA/bevacizumab & Degenerative eye disease of the central retina & 89 \\
\hline $\begin{array}{l}\text { Hydrophilic tea } \\
\text { polyphenol (TP) }\end{array}$ & 10-Hydroxycamptothecin (HCPT) & $\begin{array}{l}\text { Inhibition of proliferation and malignant transformation of } \\
\text { liver cancer cells }\end{array}$ & 99 \\
\hline PVP & Artemisinin poly ART/butyl adipate (HB) & $\begin{array}{l}\text { Inhibits the proliferation of cancer cells and the growth of } \\
\text { Plasmodium }\end{array}$ & 101 \\
\hline $\mathrm{Ag} / \mathrm{PCL}$ & Gentamicin/poloxamer & Prevention of surgical infection & 110 \\
\hline Sodium alginate (SA)/PVP & $\begin{array}{l}\text { Calcium ions/Chinese forest frog skin peptides } \\
\text { (RCSPs)/PVP }\end{array}$ & Quick hemostasis to promote wound healing & 127 \\
\hline
\end{tabular}

electrospinning, needle-less electrospinning and melt electrospinning. Sun prepared pharmorubicin loaded core/sheath PCL/PLGA nanofiber by emulsion electrospinning, using a single nozzle and emulsion as the electrospinning stock solution. The result showed that the release and degradation of drug can be accelerated by reducing the content of PCL in the sheath. ${ }^{91}$ Electrospinning is usually carried out in far-field mode (receiving distance $=5-15 \mathrm{~cm}$ ), while using the high voltage of $10-20 \mathrm{kV}$. When the receiving distance is reduced to $500 \mu \mathrm{m}$ to $5 \mathrm{~cm}$ (near-field electrospinning), the electric field is concentrated between the spinneret and the collector, while the voltage used will be much reduced. ${ }^{\mathbf{9}}$ Electrospinning usually uses hollow needles as spinnerets and a metal substrate (such as aluminum foil) as collection electrodes. Hollow needle array (multi-needle electrospinning) can be used instead of single needle to improve the production efficiency of electrospinning. ${ }^{93}$ The industrial production of electrospinning can be realized by replacing the hollow needle with a large surface area substrate (needle-free electrospinning). Fang used a tube spinneret with an array of holes to increase the output of fibers in needle-free electrospinning..$^{\mathbf{9 4}}$ Nanofibers can be prepared by melt electrospinning when polymers were in the absence of appropriate solvent at room temperature. The electrospinning stock solution is melt polymer and the vacuum system was applied to drive electrospinning. Melt electrospinning has the advantages of environmental safety, solvent-free evaporation. It has great potential in the production of biodegradable polymer fibers with controllable diameter and good uniformity. ${ }^{95}$

\section{Biological and medical applications}

The application of electrospun fibers in the field of biomedicine is mainly in four aspects: drug controlled release, biological dressing, tissue repair and enzyme immobilization.

\subsection{Drug controlled release}

5.1.1. Antineoplastic drugs. Liu prepared dichloroacetate (DCA) loaded PLA electrospun fibers, and controlled the release of therapeutic concentration of DCA from electrospun mats to suppress cervical carcinoma in vivo. ${ }^{\mathbf{9 6}} \mathrm{Yu}$ first synthesized hollow copper silicate using hydrothermal methods, then loaded trametinib into the hollow copper silicate, and finally incorporated the drug-loaded copper silicate into the polymer solution to electrospin prepare drug-loaded fibers. The composite fibers exhibited excellent photothermal effects and controlled near-infrared irradiation (NIR)-triggered drug release, leading to distinctly synergistic chemo-photothermal therapy of skin melanoma. Furthermore, such fibers could promote proliferation and attachment of normal skin cells and accelerate skin tissue healing in both tumor-bearing mice and diabetic mice by stimulating both revascularization and reepithelialization. ${ }^{97}$ Ramírez-Agudelo fabricated doxorubicin (Dox) loaded hybrid nanofibers composed of hydroxyapatite nanoparticles (nHA), poly- $\varepsilon$-caprolactone (PCL) and gelatin (Gel) by electrospinning. Both nHA and Dox were dispersed in different PCL/Gel ratio (70:30, $60: 40$, and $50: 50 \mathrm{wt} \%$ ) solutions to form three kinds of electrospun nanofibers. The three kinds of obtained fibers showed the same burst release profile in vitro Dox release due to the high solubility of the Gel in the release medium. The hybrid fibers not only had antibacterial properties, but also had an antitumor effect, especially for A-431 cancer cells. ${ }^{98}$ A local drug delivery system made of an emulsion electrospun polymer patch was developed, which contained hydrophobic 10-hydroxycamptothecin (HCPT) and hydrophilic tea polyphenol (TP) in the shell and core of the nanofiber, respectively. HCPT and TP exhibited sustained and sequential releases due to the core-shell structure of the electrospun fibers (first release of HCPT, followed by release of TP), HCPT was used to inhibit the proliferation and malignant transformation of hepatoma, while TP was used to reduce oxygen free radicals in order to prevent tumor cell metastasis. ${ }^{99}$ Che first prepared paclitaxel encapsulated PCL fibers with diameters of about several tens of nanometers to $10 \mathrm{~nm}$ by electrospinning, and then the polymer microspheres composed of anti-cancer therapeutic gene miRNA-145 were coated over the paclitaxel-loaded nanofibers. The synergistic effect of nanofibers and nanoparticles was significant, which could significantly inhibit the growth of liver tumors and prevent the metastasis of liver tumors. ${ }^{61}$ Yuan synthesized doxorubicin-loaded electrospun fibers using hydrophilic doxorubicin hydrochloride (Dox- $\mathrm{HCl}$ ) and hydrophobic free doxorubicin (Dox-base) as model drugs, and PLA as a drug carrier matrix. The drug release profiles of the prepared fibers were investigated with regard to drug-polymer miscibility, fiber wettability, and degradability. When the 
hydrophilic Dox-HCl was mixed with the PLA solution, the drug molecules formed larger agglomerates on the fiber surface or in the fiber core due to poor drug-polymer compatibility, and the aggregation of the drug in the fiber surface promoted its rapid release. The hydrophobic free doxorubicin was well dispersed in the PLA matrix and the drug release was slow. When dimethyl sulfoxide was used as the solvent for Dox- $\mathrm{HCl}$, the miscibility of drug in the polymer matrix was significantly improved, and the drug-loaded electrospun fibers with uniform drug distribution in the polymer matrix were obtained, while the drug release from these fibers was slowest, and this slow release led to a lower toxicity to hepatocellular carcinoma. ${ }^{\mathbf{1 0 0}}$ In order to preserve the bioavailability of the drug, poly(butylene adipate) (HB) acting as a crystal suppressant of artemisinin (ART) was used as the core material, poly(vinylpyrrolidone) (PVP) was selected as the shell material, and an artemisinin loaded selfsupporting nanofiber membrane was prepared by coaxial electrospinning. In vitro experiments showed that the drug-loaded fibers had a good inhibitory effect on cancer cell proliferation and Plasmodium growth. ${ }^{\mathbf{1 0 1}}$ Wang fabricated a mesh for rapamycin delivery via electrospinning using two biodegradable materials PLA and PEO as the carrier. The drug in the fiber membrane could be delivered in a targeted manner to the site of the tumor. ${ }^{102}$ The surface modification of electrospun nanofibers with specific functional groups can achieve targeted capture of circulating tumor cells (CTCs), and the capture efficiency depends on the size and morphology of the nanofibers. In the study of Ma, beaded PS electrospun nanofibers were three-layer modified by biotin-BSA, streptavidin-biotin, and biotinylated anti-EpCAM, and the capture efficiency of human breast cancer cells (MCF7) by the modified fiber was $89.2 \%$, while the capture efficiency of three-layer modified smooth electrospun PS microfibers and nanofibers of MCF7 were 78.2\% and $83.1 \%$ respectively. Fig. $6 \mathrm{~A}$ is a surface modification process diagram of electrospun nanofibers. Fig. $6 \mathrm{~B}$ is a scanning electron micrograph of MCF7 captured by three-layer modified beaded PS electrospun nanofibers, MCF7 were trapped in traps that were formed by the construction of a three-dimensional fiber network, and the trap effects helped capture tumor cells with high efficiency. ${ }^{103}$

5.1.2. Anti-inflammatory painkillers. Potrc explored electrospun PCL nanofibers as a novel nano-delivery system adopted for the oromucosal administration of poorly watersoluble drugs (ibuprofen or carvedilol). The molecular weight and solubility of the drug affected the release of the drug from the PCL matrix. The drug-loaded PCL nanofibers released almost $100 \%$ of incorporated ibuprofen in $4 \mathrm{~h}$, while only $77 \%$ of incorporated carvedilol was released during the same time period. ${ }^{104}$ Canbolat first compounded naproxen (NAP) with cyclodextrin (CD) to form an inclusion complex (NAP-CD-IC), and then incorporated the NAP-CD-IC into PCL nanofibers via electrospinning. The study of NAP showed that the PCL/NAPCD-IC nanofibers had a higher release amount of NAP than that of PCL/NAP electrospun nanofibers, which was due to the solubility enhancement of NAP by the CD inclusion complex. ${ }^{\mathbf{1 0 5}}$ Lu used indomethacin as a model drug, with ethyl cellulose (EC) and zein as polymers to synthesize nanocomposite fibers by electrospinning. In vitro dissolution tests revealed that zein/EC nanofibers possessed a sustained controlled drug release profile, which complied with Fickian diffusion. ${ }^{59}$ Single and binary ketoprofen-loaded ultrathin fiber mats were developed by Basar using electrospinning. The single fiber mat was prepared by solution electrospinning of PCL with ketoprofen at a certain weight ratio. The binary fiber mat was fabricated by emulsion electrospinning of a PCL-in-gelatin stable oil-in-water $(\mathrm{O} / \mathrm{W})$ emulsion, where ketoprofen-containing PCL solution was used as the oil phase. In vitro studies showed that, in comparison to the single fiber mat, the binary PCL/gelatin fiber mat significantly hindered ketoprofen burst release and exhibited a sustained release capacity of the ketoprofen for up to 4 days. In addition, the binary PCL/gelatin fiber mat enhanced the adhesion and proliferation of mouse L929 fibroblasts, which was beneficial for use as a novel wound dressing with a good controlled capacity to release drugs. ${ }^{106}$

5.1.3. Antibacterials. Castillo-Ortega prepared amoxicillin/ cellulose acetate (CA)-CA/PVP core-shell fibers by coaxial electrospinning using CA as the inner spinning polymer, and CA and PVP as the outer spinning macromolecules. The release of amoxicillin in the fiber nuclear layer increased with an increase of $\mathrm{pH}$. The release of moxilin was $61 \%$ with $\mathrm{pH}=3$, while the release of amoxicillin was $79 \%$ with $\mathrm{pH}=7.2 .{ }^{107}$ Yang first fabricated antibacterial curcumin encapsulated micelles which assembled from the biodegradable PEG-PCL copolymer, then blended the drug-loaded micelle powder with antitumor
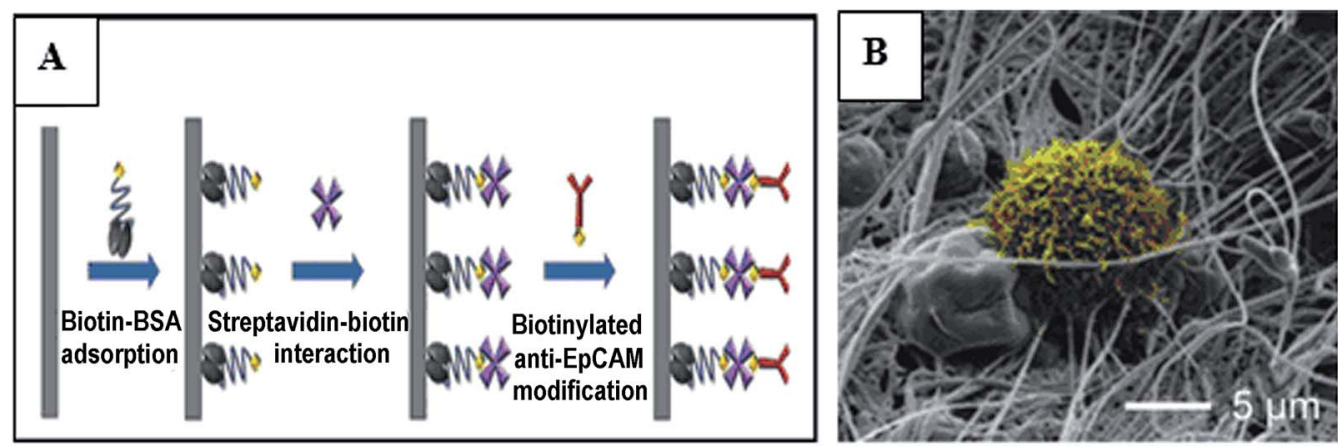

Fig. 6 (A) Surface modification process diagram of the electrospun nanofibers, (B) SEM of MCF7 captured by three-layer modified beaded PS electrospun nanofibers. 
doxorubicin in a PVA solution to form a combination. Finally, the two drug-loaded fibers were prepared by electrospinning the combination. The drugs release behaviors showed a timeprogrammed release due to the different domains of the two drugs within the nanofibers. ${ }^{108}$ The use of electrospinning to load a variety of antibacterial drugs in a reasonable manner can play a synergistic role for drugs. Two hydrophilic drugs, metronidazole and ciprofloxacin hydrochloride, were loaded individually and in combination into the PCL matrix by Zupancic using electrospinning. The result showed that the combination of drugs of the two antibacterial-loaded fibers had beneficial effects by inhibiting the growth of pathogenic bacterial in periodontal diseases. ${ }^{109}$ Nanofiber-based core/shell structured surgical sutures with gentamicin/ploxanic F127 as the core and silver/PCL as the shell were prepared by Chen using coaxial electrospinning. The core-shell fiber suture could kill bacteria more effectively compared with gentamicin or silver loaded nanofiber sutures alone. In addition, the core/shell structured surgical suture had no obvious effect on dermal fibroblasts and keratin formation, showing great potential in preventing surgical infection. ${ }^{110}$ De Cassan modified electrospun PCL fibers by grafting chitosan with the binding mechanism. The surface of the modified fiber was coated with chitosan containing amino cations, so that it could adsorb ciprofloxacin-loaded nanoparticles (silica particles) which have an opposite charge. Studies showed that the release of drugs was affected by the type of the drug delivery system attached at the fiber surface. In addition, the initial attachment, proliferation, and activity of cells of the chitosan modified fibers were improved, which was beneficial to their application in tissue engineering. ${ }^{111}$ A multi-layer coaxial fiber membrane was fabricated by Han using triaxial electrospinning, which encapsulated nisin in the core, a hydrophobic PCL as an intermediate layer, and a hygroscopic cellulose acetate as the shell. The antibacterial properties of the three-layer coaxial fiber membrane against Staphylococcus aureus were evaluated using a modified version of AATCC 100 and AATCC 147 experiments. The AATCC 147 test showed that the antibacterial activity of the three-layer coaxial fiber membrane could last for 7 days. AATCC 100 quantitative experiments showed that the three-layer coaxial electrospun fiber membrane could provide $>99.99 \%$ bactericidal effect for up to 5 days. Compared with the drugloaded core/shell and uniaxial fiber membrane, the drugloaded three-layer coaxial fiber membrane had stronger and longer-lasting antibacterial activity. ${ }^{112}$ The antimicrobial oligomer (AO) is a compound covalently bound by two molecules of ciprofloxacin (CF). Wright synthesized AO loaded polycarbonate aminoester (PCNU) nanofiber scaffold material by a one-step blend electrospinning process using a single solvent system. By optimizing the electrospinning process parameters, the drug could be loaded into the fiber by electrospinning without phase separation, and a fiber scaffold material with ideal structure could be synthesized. ${ }^{113}$ Membranes with sustained drug delivery were prepared by electrospinning metronidazoleloaded halloysite nanotubes (HNT-MNA) doped gelatin (PG) solution by Xue. The prepared membranes could be used as guided tissue regeneration/guided bone regeneration membranes. The MNA loaded halloysite nanotubes incorporated in the microfibers allowed for a sustained drug release over 20 days, compared to 4 days of the PG/MNA fibers which directly add MNA into the fibers. The antibacterial activity of the drug-loaded membrane was evaluated by using the common Clostridium nucleatum strain as the model bacteria. The result showed that the drug-loaded PG/MNA, PG/HNT-MNA, and PGMNA/HNT-MNA produced inhibitory circles. The PG/HNT sample without drug loading showed no bacteriostatic effect (Fig. 7A). After different incubation times, the inhibition zone diameter of PG-MNA/HNT-MNA was the largest on the first day, and the inhibition zone was maintained for a long time, confirming that metronidazole encapsulation in nanotubes has no adverse effect on drugs and can maintain long-lasting antibacterial activity (Fig. 7B). ${ }^{114}$

5.1.4. Other classes. A poly(methyl vinyl ether-alt-maleic ethyl monoester) nanofiber membrane loaded with salicylic acid, methyl salicylate, and capsaicin was prepared by uniaxial electrospinning. After the drugs were loaded into the fiber, its
A

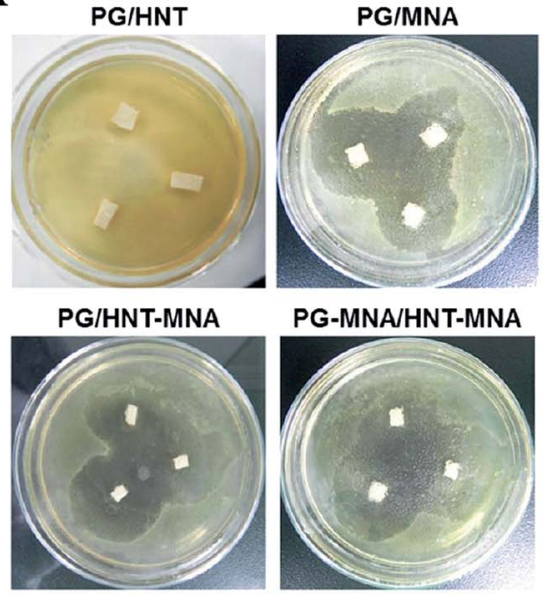

B

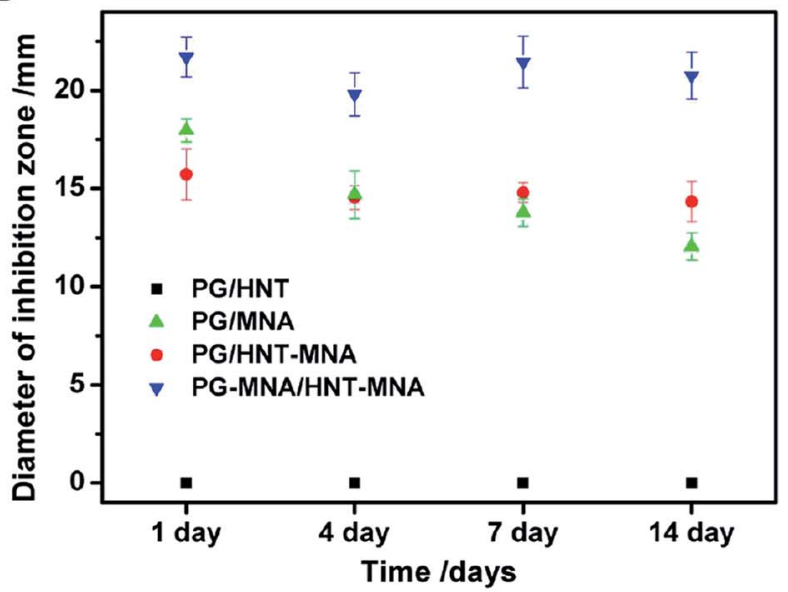

Fig. 7 Inhibition of bacterial growth of the fiber membranes: (A) photograph of the inhibition zone around the fibrous membrane on agar plates after incubation at $37^{\circ} \mathrm{C}$ for 1 day under anaerobic conditions, (B) a plot of the inhibition zone diameter versus the incubation time. 
capacity to activate the transient receptor potential cation channel 1 (TRPV 1) was improved, which was effective in treating psoriasis. The drug loading rate of the prepared fiber membrane was high and stable. Gas chromatography-mass spectrometry (GC-MS) results showed that, except for methyl salicylate, the drugs loaded in the fiber were almost unchanged after 15 days of preparation. After the drugs-loaded fiber membrane was placed on the arm of a psoriasis volunteer for 8 hours, redness was observed due to the action of capsaicin released on the skin surface by the degradation of the nanofibers. ${ }^{115}$ Growth factors and insulin loaded PLGA electrospun nanofibers were prepared by Haider using electrospinning, and the obtained drug-loaded fibers could be effectively used for targeted drug delivery. ${ }^{\mathbf{1 1 6}}$ Lancina fabricated insulin loaded chitosan-based nanofiber membranes by electrospinning using chitosan and PEO mixed in a suitable proportion as an electrospinning polymer. The bioactivity of insulin was not reduced by electrospinning. The insulin release behavior was related to the proportion of chitosan and PEO, and a low PEO content resulted in a smaller fiber diameter and a faster insulin release rate. ${ }^{117}$ Zhu prepared a degradable and biocompatible lovastatin composite biomaterial by electrospinning using polylactic acid (PLA) as the drug carrier. The drug encapsulation rate of the composite biomaterial was high (72-82\%). A drug release study in vitro showed that the drug release was divided into two stages: an initial rapid release on the first day and a slower release on the second stage which approached a plateau after the seventh day. Electrospun PLA fiber material provided a new approach to the administration of lovastatin. ${ }^{\mathbf{1 1 8}}$ In order to improve the bioavailability of the antihypertensive drug carvedilol, Chen synthesized a novel drug delivery system based on self-assembled liposome from multi-layered fiber membranes. The delivery system was composed of a drug-loaded electrospun fiber layer (the drug in this layer could self-assemble into liposome when exposed to water), an adhesion layer (the layer prolonged the residence time of the drug system in the mouth), and a support layer. The drug encapsulation efficiency was greatly affected by the molecular weight of the electrospun polymer PVP. Compared with the direct use of carvedilol, this new drug delivery system had increased drug penetration and increased bioavailability by $154 \% .{ }^{119} \mathrm{~A}$ ferulic acid (FA)/cellulose acetate (CA) core/shell structure drug loaded fiber was prepared by Yang using a improved triaxial electrospinning technique. In the electrospinning process, Yang used a spinnable polymer solution containing ferulic acid (FA) as the inner electrospinning solution, a spinnable cellulose acetate (CA) solution as the intermediate layer, and a non-spun mixed solvent as the outer electrospinning solution. In vitro experiments showed that drug loaded fibers could provide a zero-order release over 36 hours without an initial burst release. This method provided a new tactics to design a drug delivery system for similar drugs for the treatment of cardiovascular and cerebrovascular diseases. ${ }^{\mathbf{1 2 0}}$

Electrospun nanofibers have many advantages as drug delivery systems, and have been studied for many years as transdermal, oral, injection dosage forms. Examples of electrospun fibers used to deliver multiple types of drugs are also given above and summarized in Table 4 . However, the study of

Table 4 The application of electrospinning in drug controlled release

\begin{tabular}{|c|c|c|c|}
\hline Types of drugs & Electrospun polymers & Drug molecules & References \\
\hline \multirow[t]{8}{*}{ Antineoplastic drugs } & PLA & Dichloroacetate (DCA) & 96 \\
\hline & PCL, gelatin & Doxorubicin (Dox) & 98 \\
\hline & PEG, PLGA & $\begin{array}{l}\text { 10-Hydroxycamptothecin (HCPT)/hydrophilic tea } \\
\text { polyphenol (TP) }\end{array}$ & 99 \\
\hline & PCL & Paclitaxel & 61 \\
\hline & PLA & Doxorubicin (Dox)/doxorubicin hydrochloride (Dox-HCl) & 100 \\
\hline & PVP, HB & Artemisinin (ART) & 101 \\
\hline & PLA, PEO & Rapamycin & 102 \\
\hline & PS & Biotin-BSA/streptavidin-biotin/biotinylated anti-EpCAM & 103 \\
\hline \multirow{4}{*}{$\begin{array}{l}\text { Anti-inflammatory } \\
\text { painkillers }\end{array}$} & PCL & Ibuprofen or carvedilol & 104 \\
\hline & PCL & Naproxen (NAP) & 105 \\
\hline & EC, zein & Indomethacin & 59 \\
\hline & PCL, gelatin & Ketoprofen & 106 \\
\hline \multirow[t]{8}{*}{ Antibacterials } & CA, PVP & Amoxicillin & 107 \\
\hline & PEG, PCL & Curcumin/doxorubicin & 108 \\
\hline & PCL & Metronidazole/ciprofloxacin & 109 \\
\hline & PCL & Gentamicin/Ag & 110 \\
\hline & PCL, chitosan & Ciprofloxacin & 111 \\
\hline & PVP, PCL, cellulose acetate & Nisin & 112 \\
\hline & PCNU & Antimicrobial oligomer (AO) & 113 \\
\hline & PCL, gelatin & Metronidazole & 114 \\
\hline \multirow[t]{6}{*}{ Other classes } & $\begin{array}{l}\text { Poly(methyl vinyl ether-alt-maleic ethyl } \\
\text { monoester) }\end{array}$ & Salicylic acid/methyl salicylate capsaicin & 115 \\
\hline & PLGA & Growth factors & 116 \\
\hline & Chitosan, PEO & Insulin & 117 \\
\hline & PLA & Lovastatin & 118 \\
\hline & PVP & Carvedilol & 119 \\
\hline & CA & Ferulic acid (FA) & 120 \\
\hline
\end{tabular}


drugs release mechanism and pharmacokinetics of drug-loaded electrospun nanofibers is still very few, which would limit the practical application.

\subsection{Biological dressings}

Electrospun fibers have good gas permeability and can provide a biomimetic environment for skin cell regeneration during wound healing. The small pore size distribution of the fiber membrane can also effectively block the invasion of bacteria, which is suitable for skin dressings and artificial imitation skin (Fig. 8). ${ }^{\mathbf{1 2 1}}$ In addition, the electrospun fiber membrane has a large specific surface area and can be loaded with drugs to promote the rapid recovery of damaged skin. Croisier prepared polyelectrolyte polysaccharide (chitosan and hyaluronic acid) coated PCL fiber composites by combining electrospinning with a layer-by-layer deposition technique. Chitosan and hyaluronic acid were deposited on the surface of the electrospun PCL fibers by opposite charge attraction. Cell culture tests corroborated the potential use of the prepared composite in wound healing. ${ }^{122}$ Bismethoxyglycine (DMOG) was loaded into PCL/type I collagen (COLI) core/shell electrospun nanofibers by Gao to prepare a functional diabetic wound dressing. In the treatment of diabetic ulcers, the prepared drug-loading core/shell nanofiber could effectively control the release of DMOG, and effectively stabilize the hypoxia-inducible factor (hif-1 $\alpha$ ) in vitro and in vivo, and thus trigger transcription of downstream genes, which promote diabetes wounds' re-epithelialization, angiogenesis, and wound healing. ${ }^{123}$ Based on the application of honey for tissue regeneration, Sarkar used electrospinning to prepare honey/polyvinyl alcohol (PVA) fiber scaffolds. The study showed that a low content of honey in electrospun fibers could provide a more favorable internal microenvironment for tissue regeneration. Fiber scaffolds containing 1\% honey had high antibacterial properties, and scaffolds containing $0.5 \%$ honey had high antioxidant and anti-inflammatory properties. ${ }^{\mathbf{1 2 4}}$ After preparing PCL nanofibers by electrospinning, a solution of chitosan (CS)-based NO was dropped onto the nanofibers to prepare CS-NO coated PCL/CS-NO wound dressings. PCL/CSNO wound dressings could promote re-epithelialization and granulation formation, effectively improve the tissue structure of the regenerated tissue at the epidermal-dermal junction, and accelerate the wound healing process. ${ }^{\mathbf{1 2 5}}$ Trinca prepared double-layer fibers for skin wound repair materials by electrospinning, one layer was the mechanical support which was composed of PCL or PCL/cellulose acetate blend (PCL/CA), and the other layer was the wound dressing which consisted of chitosan/poly(ethylene oxide) (CHI/PEO). The fibers had low cytotoxicity to L929 fibroblasts and could promote adequate cells proliferation, which met the requirements of wound dressings for skin lesion. ${ }^{96}$ Mahmoudi added graphene oxide to a polymer mixed solution of chitosan, PVP, and PEO to electrospin in order to obtain a nanofiber membrane (fiber diameter of about $60 \mathrm{~nm}$ ), whose mechanical property was close to that of natural skin. The prepared nanofiber membrane could be used for temporary skin grafting. The graphene oxide nanoflakes embedded in the fibers had a good effect on acute wound healing in adult male rats, and 14 days after the operation, large open wounds $\left(1.5 \times 1.5 \mathrm{~cm}^{2}\right)$ were completely regenerated.126 $\mathrm{SA} @ \mathrm{Ca}^{2+} / \mathrm{RCSPs}$ core/shell nanocomposite fibers were prepared by $\mathrm{Li}$ with a coaxial electrospinning technology using a PVP solution containing calcium ions and Chinese wood frog skin peptides (RCSPs) as the core spinning solution, and a PVP solution containing sodium alginate (SA) as a shell solution. In vivo experiments in black rats showed that the composite nanofibers could quickly stop bleeding and effectively promote wound healing. The healing rates of SA@ $\mathrm{Ca}^{2+} /$ RCSPs nanofiber treated wounds on days 5 and 15 were $46.65 \%$ and $97.46 \%$, respectively. ${ }^{127}$ Sundaran placed ampicillin-loaded chitosan microbeads into two layers of PCL electrospun fibers to form a sandwich structure material

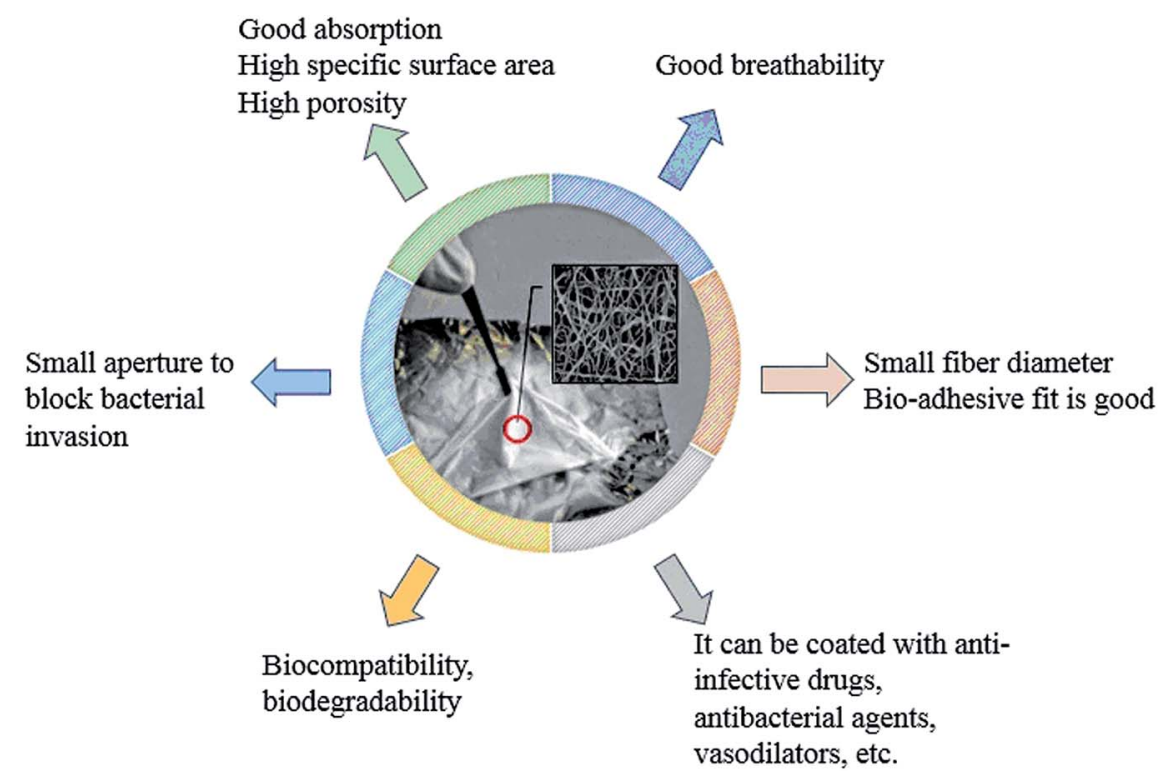

Fig. 8 Characteristics of electrospun nanofibers and their applications in biological dressings. 
(MbAPPCL). An in vitro cytotoxicity assay of L-929 fibroblasts by direct contact and elution methods revealed that MbAPPCL had non-cytotoxic properties. Cell adhesion and activity assays further found that MbAPPCL was cyto-compatible as a wound dressing. The hemolysis rate and platelet adhesion rate indicated that MbAPPCL had blood compatibility. A susceptibility test of MbAPPCL to Staphylococcus aureus also showed its excellent antibacterial properties. ${ }^{\mathbf{1 2 8}}$

Electrospun fibers have made great progress in wound dressings, but there are still many areas need to be improved. For example, the fabrication of new structure nanofibers for wound healing, and the combination of electrospinning and 3D printing technology. The electrospun fibers can also be combined with electrical stimulation, pressure, magnetic force and other external forces to play a better role.

\subsection{Tissue repair}

Electrospinning enables the preparation of continuous ultrafine fibers with diameters similar to those of natural extracellular matrices (ECMs). Electrospun nanofiber scaffolds can thus mimic the structure of ECMs in humans to a great extent. Electrospun fiber membranes or fiber mats have high porosity, good pore connectivity, a large specific surface area and biocompatibility, which provide a good microenvironment for cell survival to help cells adhere, differentiate, and proliferate. The thickness, the three-dimensional structure, and mechanical properties of the electrospun nanofiber scaffold can be regulated by adjusting the electrospinning parameters. Moreover, bioactive molecules (such as growth factors, cell regulators, and even living cells) and inorganic particles (such as hydroxyapatite) could be added into to nano-scaffolds in electrospinning, which give electrospun fiber scaffolds a variety of functions. Electrospun nanofiber materials are widely used in the field of tissue repair such as trachea, nerves, skin, cartilage, bones, blood vessels, tendons, and ligaments.

Hinderer prepared proteoglycan, PCL, gelatin hybrid matrix electrospun fibers for tracheal tissue repair. Studies showed that human bronchial cells could attach, migrate, and maintain their phenotype on the electrospun hybrid matrix fibers. ${ }^{\mathbf{1 2 9}}$ Farrugia combined "electrospinning" with a computer "programmable $x-y$ mode" to prepare a three-dimensional porous cell-invasive PCL fiber scaffold with a porosity of $87 \%$. The fiber diameter was $7.5 \pm$ $1.6 \mu \mathrm{m}$, the inter-fiber distances were 8-133 $\mu \mathrm{m}$ with an average of $46 \pm 22 \mu \mathrm{m}$. The porous structure of the fiber scaffold could facilitate cell immersion. In vitro experiments showed that the cells could fully penetrate the fiber scaffold after 14 days. ${ }^{\mathbf{1 3 0}}$ Kador fabricated a biodegradable PLA electrospun scaffold to direct the radial growth of retinal ganglion cell (RGC) axons. An increase in RGC survival was observed with this scaffold, and there was no significant change in electrophysiological properties of RGC. $81 \%$ of RGCs projected axons radially along the scaffold fibers, facilitating the use of cell transplantation therapy for glaucoma and other retinal degenerative diseases. ${ }^{\mathbf{1 3 1}}$ Gustafsson prepared polyethylene terephthalate (PET) and polyurethane (PU) nanofiber scaffolds by uniaxial electrospinning and studied their biocompatibility. The results showed that the size of electrospun PET or
PU fibers matched the size of ECM fibers, and the specific surface area of the electrospinning fiber scaffold was large. The prepared electrospun fiber scaffolds were suitable for cell attachment and proliferation. ${ }^{63}$ Vaquette cultured osteoblasts in the alveolar bone and prepared PCL electrospun fiber membranes to cultivate periodontal ligament cells. Electrospun fibers could form a supporting network around the cells to provide fixed anchor points for cells and promote cell adhesion and proliferation. ${ }^{\mathbf{1 3 2}} \mathrm{Xi}$ prepared a hybrid biomimetic skin repair tissue engineering scaffold by electrospinning. The hybrid nanofibrous scaffold was composed of polycitrate-polylysine (PCE) and PCL. The scaffold had tissue elasticity, high antibacterial activity, and could effectively prevent bacterial infection of wounds. The scaffold could also promote wound healing and enhance the regeneration of skin. In PCL-PCE nanofibrous scaffolds, a high PCE content in the scaffold had strong antibacterial ability against normal bacteria and multi-drug resistant bacteria (MDR). After incubation with the PCL-PCE nanofibrous scaffold for $2 \mathrm{~h}$, significant morphological changes occurred in E. coli. The intact cell structure was destroyed and the cell membrane was depressed, indicating that the antibacterial performance of the PCL-PCE nanofibrous scaffold was good (Fig. 9). The scaffold could also significantly promote complete wound healing and skin regeneration in a mouse model. ${ }^{133}$ Luo put primary embryonic motor neurons obtained from $\mathrm{C} 2 \mathrm{C} 12$ cells on an electrospun PLA nanofiber scaffold. The PLA nanofiber scaffold could guide C2C12 cells to grow in the direction of the fiber arrangement to form myotubes. ${ }^{134}$ Organic/inorganic nanofibrous scaffolds with nanosilicate in a PCL fiber matrix were successfully fabricated by Wang via electrospinning. The nanosilicates-doped nanofibers were capable of inducing bone formation better than pure PCL nanofiber samples due to the use of nanosilicates consisting of hydrous sodium lithium magnesium silicate. ${ }^{135}$ Scaffolds with a shish-kebab (SK) structure formed by PCL nanofibers and chitosan-PCL (CS-PCL) copolymers were prepared by Jing by combining electrospinning with a subsequent crystallization. The introduction of chitosan into PCL electrospun nanofibers enhanced the affinity of the PCL scaffold for cells. When the ratio of PLC to chitosan in the chitosan-PLC copolymer was $8: 8$, the scaffold PCL-SK $\left(\mathrm{CS}-\mathrm{PCL}_{8.8}\right)$ had a distinct shishkebab heterostructure. Water contact angle and biomimetic activity experiments showed that the shish-kebab PCL-SK (CS$\mathrm{PCL}_{8.8}$ ) scaffold had stronger hydrophilicity and mineralization
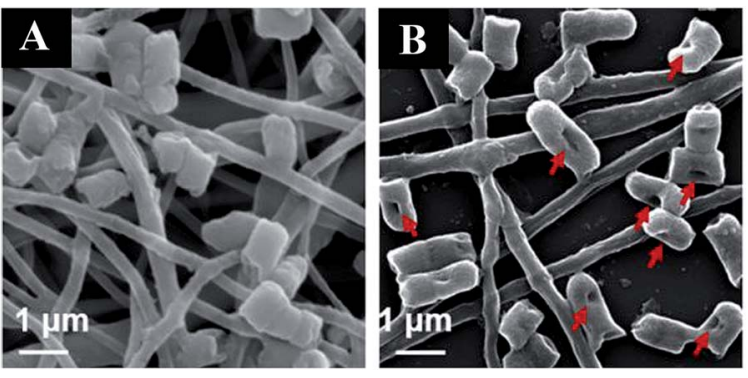

Fig. 9 SEM of morphological changes of E. coli cultured with PCL and PCL-30\% PCE electrospun nanofibers after 2 days: (A) PCL electrospun nanofibers, (B) PCL-30\% PCE electrospun nanofibers, red arrows indicate morphological changes of bacterial cell membranes. 
ability than the electrospun smooth PLC fiber and shish-kebab PCL-SK (PCL) scaffold. PCL-SK (CS-PCL 8.8 ) scaffolds also exhibited good cell adhesion, cell viability, and metabolic activity for MG63 osteoblasts, indicating that the scaffold had potential application for bone tissue engineering. ${ }^{136}$ A glucosamine (GA)loaded PEG/PLA scaffold was synthesized by Mirzaei using electrospinning for cartilage tissue engineering. After 5 days of culture of chondrocytes on the scaffold, the addition of GA was found to increase the amount of protein adsorption on the scaffold, thereby enhancing the adhesion of the scaffold to the cells (Fig. 10A-D). In addition, the molecular weight of the polymer also had an effect on cell adhesion (Fig. 10A-D). The binding of PEG with a high molecular weight $\left(M_{\mathrm{w}}=20000\right)$ to GA could promote the adhesion of scaffolds to cells (Fig. 10D). ${ }^{\mathbf{1 3 7}}$ Piai loaded chondroitin sulfate (CS) onto PCL nanofibers by electrospinning. The human articular chondrocytes maintained their unique circular and cell agglomeration characteristics on CS-loaded PCL fibers, which was beneficial to the application of fibers in cartilage tissue repair. ${ }^{138}$

Electrospun fibers have been used to repair a variety of tissues as shown above and summarized in Table 5. Current studies have shown that electrospun fibers mainly repair tissue by directly interfering with cell orientation and proliferation, affecting cell mobility, changing cell morphology, interfering with cell differentiation. However, these studies are far from enough. As a substitute for functional tissue, it is necessary to further deepen its action mechanism.

\subsection{Enzyme immobilization}

The high specific surface area and porosity of the electrospun fibers can effectively alleviate the diffusion resistance of the matrix and greatly improve the catalytic ability of the loaded
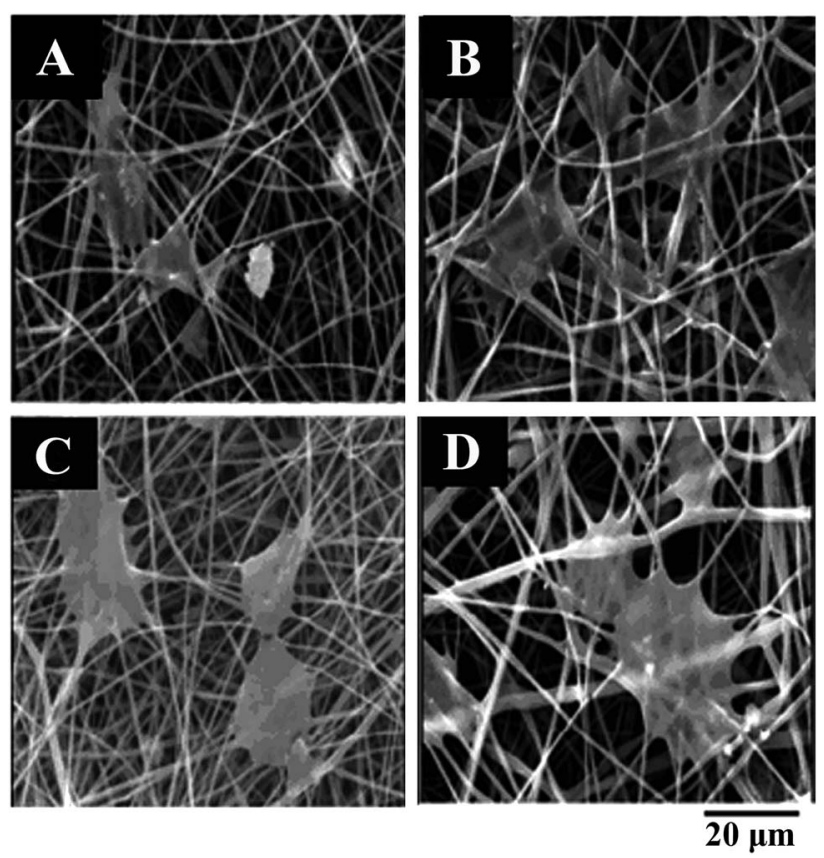

Fig. 10 SEM of scaffold chondrocyte culture after 5 days: (A) PLA-PEG $\left(M_{\mathrm{w}}=3000\right)$, (B) PLA-PEG $\left(M_{\mathrm{w}}=3000\right)-\mathrm{GA}$, (C) PLA-PEG $\left(M_{\mathrm{w}}=\right.$ 20 000), (D) PLA-PEG $\left(M_{w}=20\right.$ 000)-GA. enzyme. The method of enzyme immobilization in electrospun fibers is mainly the surface loading method (such as the active functional group loading method, chemical crosslinking, and surface modification). Basturk immobilized $\alpha$-amylase by surface covalent bonding to electrospun polyvinyl alcohol/ polyacrylic acid (PVA/PAA) nanofibers with diameters ranging from 100 to $150 \mathrm{~nm}$. The immobilized $\alpha$-amylase was more resistant to temperature inactivation than free $\alpha$ amylase. ${ }^{139}$ The keratinolytic protease immobilized PVA electrospinning nanofibers were fabricated by impregnating PVA electrospinning nanofibers into protease solution. The keratinolytic protease immobilized on the PVA nanofibers enhanced the activity and stability even at an higher temperature and a wider $\mathrm{pH}$ range. ${ }^{\mathbf{1 4 0}}$ The amylase and protease were covalently immobilized onto electrospun poly(styrene-comaleic anhydride) nanofibers with partial retention of their catalytic activity by incubating electrospinning fiber mat in protein solution. It was demonstrated that amylase could retain its catalytic activity when co-immobilized with protease. ${ }^{141}$ The $\mathrm{PVA} / \mathrm{Zn}^{2+}$ polymer/ionic metal composite nanofiber was prepared by electrospinning and used as carriers in lipase immobilization. The PVA $/ \mathrm{Zn}^{2+}$ composite nanofiber must be crosslinked before lipase immobilization because of the water solubility of PVA. The hydroxyl groups of PVA and the aldehyde groups of glutaraldehyde were crosslinked at room temperature for $24 \mathrm{~h}$ to obtain waterinsoluble nanofibers. Then the water-insoluble nanofibers were immersed to lipase solution to obtain lipase immobilized nanofiber. The lipase immobilized nanofiber exhibited enhanced enzymatic stability. The lipase immobilized PVA/ $\mathrm{Zn}^{2+}$ nanofiber could keep $90 \%$ activity at $70{ }^{\circ} \mathrm{C}$ after $40 \mathrm{~min}$, while the free lipase lost all its activity after the same time. ${ }^{\mathbf{1 4 2}}$ The horseradish peroxidase (HRP) immobilized magnetic $\mathrm{Fe}_{3} \mathrm{O}_{4}$ /polyacrylonitrile (PAN) electrospinning nanofibers were synthesized for phenol removal application. Firstly, $\mathrm{Fe}_{3} \mathrm{O}_{4}$ and PAN were dispersed in dimethylformamide, and stirred to obtain electrospinning stock solution. The $\mathrm{Fe}_{3} \mathrm{O}_{4} / \mathrm{PAN}$ magnetic nanofibers were prepared by electrospinning the above stock solution. Secondly, the $\mathrm{Fe}_{3} \mathrm{O}_{4} / \mathrm{PAN}$ magnetic nanofibers were surface modified using dopamine and glutaraldehyde solution. Finally, the modified fibers were immersed into the HRP solution for a certain time to obtain HRP immobilized $\mathrm{Fe}_{3} \mathrm{O}_{4} / \mathrm{PAN}$ nanofibers. The HRP immobilized $\mathrm{Fe}_{3} \mathrm{O}_{4} / \mathrm{PAN}$ electrospinning nanofibers with $40 \% \mathrm{Fe}_{3} \mathrm{O}_{4}$ nanoparticles loading had the lowest HRP loading, but had the highest activity, because of the magnetic synergy of $\mathrm{Fe}_{3} \mathrm{O}_{4}$ nanoparticles. ${ }^{\mathbf{1 4 3}}$ Compared with other enzyme carriers, electrospun fiber has more advantages. In recent years, there are more and more applications of electrospinning in enzyme immobilization. The fibers immobilizing $\beta$-D-galactosidase, ${ }^{\mathbf{1 4 4}}$ xylanase ${ }^{\mathbf{1 4 5}}$ glucose oxidase, ${ }^{\mathbf{1 4 6}}$ naringinase ${ }^{\mathbf{1 4 7}}$ and laccase ${ }^{\mathbf{1 4 8}}$ have been successfully prepared by electrospinning.

At present, the enzyme immobilization in electrospun fibers is mainly by surface loading method. Different loading modes lead to different binding capacities between enzymes and fibers. Considering new loading modes will be of great help to explore the applications of enzymes. 
Table 5 The application of electrospinning in tissue repair

\begin{tabular}{llr}
\hline Electrospun polymers & Application & References \\
\hline Proteoglycan/PCL/gelatin & Tracheal tissue repair & 129 \\
PLA & Direct the radial growth of retinal ganglion cell (RGC) axons & 131 \\
PET/PU & Bond tissue repair & 63 \\
PCL & Cultivate periodontal ligament cells & 132 \\
PCE/PCL & A hybrid biomimetic skin repair tissue engineering scaffold & 133 \\
PLA & Form myotubes & 134 \\
PCL & To induce bone formation & 135 \\
CS-PCL & Bond tissue repair & 136 \\
PEG/PLA & Culture chondrocytes & 137 \\
PCL & Cartilage tissue repair & 138
\end{tabular}

\section{Outlook}

This study reviewed the application of electrospinning technology in the biomedicine field, and focused on its application in drug controlled release, biological dressings and tissue repair. With the continuous development of electrospinning technology and equipment, some electrospun products directly sprayed onto wounds are commercially available. The batch preparation of fibers could be accomplished by needle-free electrospinning equipment. Although the batch preparation of electrospun nanofibers has achieved remarkable results, theoretical research on the formation process of the spinning cone of the needle-free electrospinning equipment is still not perfect, and the structural design of the spinning tube needs to be further developed. At present, drug loaded electrospun fibers have been applied in a variety of drug delivery forms. Considering the morphology and structure of electrospun nanofibers and the advantages of self-forming film, it is expected that transdermal drug delivery can be realized. Composite materials with multiple functions are the hotspots in the field of biomedicine. Nano gold and graphene can be combined with electrospun fibers to prepare multifunctional biomaterials. Metal-organic framework materials (MOFs) are now widely studied because their structure is adjustable and has a high specific surface area, and thus the combination of electrospinning and MOF is expected to develop new biocomposites. In addition, considering the toxicological properties of electrospun fibers, how to achieve green preparation by selecting polymers and solvents is also a challenge for electrospinning technology.

\section{Conflicts of interest}

There are no conflicts to declare.

\section{Acknowledgements}

This work was supported by the National Natural Science Foundation of China (21606147), the Key projects of industrial science and technology plan in Qiannan prefecture (2017(11)), the Innovation Project of the Shandong Academy of Medical Sciences and the Academy Science and Technology Project of Shandong Academy of Medical Sciences (No. 2017-55). Thanks to Dr Edward C. Mignot, Shandong University, for linguistic advice.

\section{References}

1 J. Aragon, S. Feoli, S. Irusta and G. Mendoza, Int. J. Pharm., 2019, 557, 162-169.

2 X. Wang, G. Y. Wang, H. L. Shan, X. Q. Wang, C. X. Wang, X. L. Zhuang, J. X. Ding and X. S. Chen, Biomater. Sci., 2019, 7, 963-974.

3 V. U. Godakanda, H. Li, L. Alquezar, L. Zhao, L. M. Zhu, R. De Silva and G. R. Williams, Int. J. Pharm., 2019, 562, 172-179.

4 N. Chinatangkul, S. Tubtimsri, D. Panchapornpon, P. Akkaramongkolporn, C. Limmatvapirat and S. Limmatvapirat, Int. J. Pharm., 2019, 562, 258-270.

5 H. Bukhary, G. R. Williams and M. Orlu, Int. J. Pharm., 2018, 549, 446-455.

6 J. Wang and M. Windbergs, Int. J. Pharm., 2019, 556, 363371.

7 Y. F. Sun, H. L. Shan, J. X. Wang, X. Q. Wang, X. Y. Yang and J. X. Ding, J. Biomed. Nanotechnol., 2019, 15, 939-950.

8 D. Annis, A. Bornat, R. O. Edwards, A. Higham and J. T. Wilson, Trans.-Am. Soc. Artif. Intern. Organs, 1978, 24, 209-214.

9 D. Kai, M. P. Prabhakaran, B. Q. Chan, S. S. Liow, S. Ramakrishna, F. Xu and X. J. Loh, Biomed. Mater., 2016, 11, 015007-015017.

10 J. Hu, D. Kai, H. Ye, L. Tian, X. Ding, S. Ramakrishna and X. J. Loh, Mater. Sci. Eng., C, 2017, 70, 1089-1094.

$11 \mathrm{X}$. Hu, S. Liu, G. Zhou, Y. Huang, Z. Xie and X. Jing, J. Controlled Release, 2014, 185, 12-21.

12 S. M. Eskitoros-Togay, Y. E. Bulbul, S. Tort, F. Demirtas Korkmaz, F. Acarturk and N. Dilsiz, Int. J. Pharm., 2019, 565, 83-94.

13 S. Maione, M. M. Pérez-Madrigal, L. J. Del Valle, A. Díaz, L. Franco, C. Cativiela, J. Puiggali and C. Aleman, J. Appl. Polym. Sci., 2017, 134, 44883-44896.

14 S. Fahimirad and F. Ajalloueian, Int. J. Pharm., 2019, 566, 307-328.

15 L. Polakova, J. Sirc, R. Hobzova, A. I. Cocarta and E. Hermankova, Int. J. Pharm., 2019, 558, 268-283. 
16 J. J. Xue, T. Wu, Y. Q. Dai and Y. N. Xia, Chem. Rev., 2019, 119, 5298-5415.

17 X. R. Feng, J. N. Li, X. Zhang, T. J. Liu, J. X. Ding and X. S. Chen, J. Controlled Release, 2019, 302, 19-41.

18 J. Wang, L. Helder, J. Shao, J. A. Jansen, M. Yang and F. Yang, Int. J. Pharm., 2019, 564, 1-9.

19 S. J. Choi, H. M. Kim and H. S. Kim, Sens. Actuators, A, 2019, 294, 194-202.

20 X. Wang, Y. Yuan, X. Huang and T. Yue, J. Appl. Polym. Sci., 2015, 132, 1-9.

21 H. Fong, I. Chun and D. H. Reneker, Polymer, 1999, 40, 4585-4592.

22 N. Bhardwaj and S. C. Kundu, Biotechnol. Adv., 2010, 3, 325347.

23 C. Wang, Y. W. Cheng, C. H. Hsu, H. S. Chien and S. Y. Tsou, J. Polym. Res., 2010, 18, 111-123.

24 J. Lasprilla-Botero, M. Álvarez-Láinez and J. M. Lagaron, Mater. Today Commun., 2018, 14, 1-9.

25 S. D. Vrieze, T. V. Camp, A. Nelvig, B. Hagstrom, P. Westbroek and K. D. Clerck, J. Mater. Sci., 2009, 44, 1357-1362.

26 V. Pillay, C. Dott, Y. E. Choonara, C. Tyagi, L. Tomar, P. Kumar and V. M. K. Ndesendo, J. Nanomater., 2013, 2013, 1-22.

27 M. Lauricella, F. Cipolletta, G. Pontrelli, D. Pisignano and S. Succi, Phys. Fluids, 2017, 29, 082003-082024.

28 M. Richard-Lacroix and C. Pellerin, Vib. Spectrosc., 2017, 91, 92-98.

29 G. Taylor, Proc. R. Soc. London, Ser. A, 1969, 313, 453-475.

30 X. P. Tang, N. Si, L. Xu and H. Y. Liu, Therm. Sci., 2014, 18, 1447-1449.

31 L. R. Manea, A. Bertea, E. Nechita, C. V. Popescu and I. Sandu, Rev. Chem., 2016, 67, 1284-1289.

32 C. S. Ki, J. W. Kim, J. H. Hyun, K. H. Lee, M. Hattori, D. K. Rah and Y. H. Park, J. Appl. Polym. Sci., 2007, 106, 3922-3928.

33 C. J. Buchko, L. C. Chen, Y. Shen and D. C. Martin, Polymer, 1999, 40, 7397-7407.

34 C. Y. Wang, J. Wang, L. D. Zeng, Z. W. Qiao, X. C. Liu, H. Liu, J. Zhang and J. X. Ding, Molecules, 2019, 24, 834-866.

35 P. P. Zhang, X. L. Jiao and D. R. Chen, Mater. Lett., 2013, 91, 23-26.

36 G. F. Yu, X. Yan, M. Yu, M. Y. Jia, W. Pan, X. X. He, W. P. Han, Z. M. Zhang, L. M. Yu and Y. Z. Long, Nanoscale, 2016, 8, 2944-2950.

37 T. Krishnamoorthy, V. Thavasi, V. Akshara, A. S. Kumar, D. Pliszka, S. G. Mhaisalkar and S. Ramakrishna, J. Nanomater., 2011, 2011, 739241-739247.

38 E. Smit, U. Buttner and R. D. Sanderson, Polymer, 2005, 46, 2419-2423.

39 E. F. Medina, S. D. Arjona, F. Z. Corrales and V. A. Borras, Dyna, 2013, 80, 109-114.

40 Y. R. Su, B. G. Lu, Y. Z. Xie, Z. W. Ma, L. X. Liu, H. T. Zhao, J. Zhang, H. G. Duan, H. L. Zhang, J. Li, Y. Q. Xiong and E. Q. Xie, Nanotechnology, 2011, 22, 285609-285614.
41 E. S. Medeiros, L. H. C. Mattoso, E. N. Ito, K. S. Gregorski, G. H. Robertson and R. D. Offeman, J. Biobased Mater. Bioenergy, 2008, 2, 231-242.

42 A. Chanthakulchan, P. Koomsap, A. A. Parkhi and P. Supaphol, Virtual Phys. Prototyp., 2015, 4, 227-237.

43 J. K. Y. Lee, N. Chen, S. Peng, L. Li, L. Tian, N. Thakor and S. Ramakrishna, Prog. Polym. Sci., 2018, 86, 40-84.

44 J. X. Ding, J. Zhang, J. N. Li, D. Li, C. S. Xiao, H. H. Xiao, H. H. Yang, X. L. Zhuang and X. S. Chen, Prog. Polym. Sci., 2019, 90, 1-34.

45 D. K. Patella, S. D. Dutta and K. Lim, RSC Adv., 2019, 9, 19143-19162.

46 G. Amariei, V. Kokol, K. Boltes and R. Rosal, RSC Adv., 2018, 8, 28013-28023.

47 J. Cai, X. J. Chen, X. J. Wang, Y. L. Tan, D. D. Ye, Y. T. Jia, P. F. Liu and H. Yu, RSC Adv., 2018, 8, 39463-39469.

48 S. Ullah, M. Hashmi, M. Q. Khan, D. Kharaghani, Y. Saito, T. Yamamoto and I. S. Kim, RSC Adv., 2019, 9, 268-277.

49 L. Chen, L. P. Shao, F. P. Wang, Y. F. Huang and F. H. Gao, RSC Adv., 2019, 9, 10494-10507.

50 Q. Zhu, Z. J. Ma, H. Y. Li, H. M. Wang and Y. H. He, RSC Adv., 2019, 9, 15582-15592.

51 N. G. Zhang, Y. L. Deng, Q. D. Tai, B. Cheng, L. B. Zhao, Q. L. Shen, R. X. He, L. Y. Hong, W. Liu, S. S. Guo, K. Liu, H. R. Tseng, B. Xiong and X. Z. Zhao, Adv. Mater., 2012, 24, 2756-2760.

52 H. Q. Liu, X. L. Yu, B. Cai, S. J. You, Z. B. He, Q. Q. Huang, L. Rao, S. S. Li, C. Liu, W. W. Sun, W. Liu, S. S. Guo and X. Z. Zhao, Appl. Phys. Lett., 2015, 106, 093703.

53 J. Zhang, S. Li, D. D. Ju, X. Li, J. C. Zhang, X. Yan, Y. Z. Long and F. Song, Chem. Eng. J., 2018, 349, 554-561.

54 Q. Jiang, N. Reddy, S. Zhang, N. Roscioli and Y. Yang, J. Biomed. Mater. Res., Part A, 2013, 101, 1237-1247.

55 D. Chouhan, B. Chakraborty, S. K. Nandi and B. B. Mandal, Acta Biomater., 2017, 48, 157-174.

56 I. Yousefi, M. Pakravan, H. Rahimi, A. Bahador, Z. Farshadzadeh and I. Haririan, Mater. Sci. Eng., C, 2017, 75, 433-444.

57 C. Marcolin, L. Draghi, M. Tanzi and S. Fare, J. Mater. Sci.: Mater. Med., 2017, 28, 80-91.

58 S. Vicini, M. Mauri, S. Vita and M. Castellano, J. Appl. Polym. Sci., 2018, 135, 1-8.

59 H. Lu, Q. Wang, G. Li, Y. Qiu and Q. Wei, Mater. Sci. Eng., C, 2017, 74, 86-93.

60 M. Seon-Lutz, A. C. Couffin, S. Vignoud, G. Schlatter and A. Hebraud, Carbohydr. Polym., 2019, 207, 276-287.

61 H. L. Che, H. J. Lee, K. Uto, M. Ebara, W. J. Kim, T. Aoyagi and I. K. Park, J. Nanosci. Nanotechnol., 2015, 15, 7971-7975.

62 A. Haider, K. C. Gupta and I. K. Kang, Nanoscale Res. Lett., 2014, 9, 314-325.

63 Y. Gustafsson, J. Haag, P. Jungebluth, V. Lundin, M. L. Lim, S. Baiguera and P. Macchiarini, Biomaterials, 2012, 33, 8094-8103.

64 T. Elakkiya, R. Sheeja, K. Ramadhar and T. S. Natarajan, J. Appl. Polym. Sci., 2013, 128, 2840-2846.

65 R. Y. Basha, T. S. Sampath Kumar and M. Doble, Macromol. Mater. Eng., 2017, 302, 1-9. 
66 K. Ma, Y. Qiu, Y. Fu and Q. Q. Ni, J. Mater. Sci., 2018, 53, 10617-10626.

67 V. Y. Chakrapani, A. Gnanamani, V. R. Giridev, M. Madhusoothanan and G. Sekaran, J. Appl. Polym. Sci., 2012, 125, 3221-3227.

68 V. A. Ganesh, S. S. Dinachali, H. K. Raut, T. M. Walsh, A. S. Nair and S. Ramakrishna, RSC Adv., 2013, 3, 38193824 .

69 G. Q. Blantocas, A. S. Alaboodi and A. B. H. Mekky, Arabian J. Sci. Eng., 2018, 43, 389-398.

70 B. Song, C. Wu and J. Chang, Regener. Biomater., 2015, 2, 229-237.

71 A. Rashid, T. Muhammad, A. Imran, A. Rehana, K. P. Noorunnisa and A. Robin, Int. J. Biol. Macromol, 2018, 120, 385-393.

72 W. Y. Lai, S. W. Feng, Y. H. Chan, W. J. Chang, H. T. Wang and H. M. Huang, Polymers, 2018, 10, 804-817.

73 Z. Mao, J. Li, W. Huang, H. Jiang, B. L. Zimba, L. Chen and Q. Wu, RSC Adv., 2018, 8, 16619-16625.

74 K. T. Shalumon, C. Sheu, C. H. Chen, S. H. Chen, G. Jose, C. Y. Kuo and J. P. Chen, Acta Biomater., 2018, 72, 121-136.

75 U. Aggarwal, A. K. Goyal and G. Rath, Mater. Sci. Eng., C, 2017, 75, 125-132.

76 M. Irani, G. M. M. Sadeghi and I. Haririan, Mater. Sci. Eng., C, 2017, 75, 165-174.

77 S. Kamonthip, M. Kanjana, P. Penwisa, C. Pisutsaran, W. Sujitra and I. Thitirat, Fibers Polym., 2018, 19, 13731378.

78 M. R. Ramezani, Z. Ansari-Asl, E. Hoveizi and A. R. Kiasat, Mater. Chem. Phys., 2019, 229, 242-250.

79 J. Zhang, T. Zheng, E. Alarçin, B. Byambaa, X. F. Guan, J. X. Ding, Y. S. Zhang and Z. M. Li, Small, 2017, 13, 1701949-1701963.

80 Y. Gao, T. W. Teoh, Q. Wang and G. R. Williams, J. Mater. Chem. B, 2017, 5, 9165-9174.

81 H. Oliveira, S. Catros, O. Castano, S. Rey, R. Siadous, D. Clift and J. Amedee, Acta Biomater., 2017, 54, 377-385.

82 A. L. Yarin, Polym. Adv. Technol., 2011, 22, 310-317.

83 A. Khalf and S. V. Madihally, Eur. J. Pharm. Biopharm., 2017, 112, 1-17.

84 Y. J. Son, W. J. Kim and H. S. Yoo, Arch. Pharm. Res., 2014, 37, 69-78.

85 A. Bhattacharjee, K. Kumar, A. Arora and D. S. Katti, Mater. Sci. Eng., C, 2016, 63, 266-273.

86 J. Jalvandi, M. White, Y. Gao, Y. B. Truong, R. Padhye and I. L. Kyratzis, Mater. Sci. Eng., C, 2017, 73, 440-446.

87 J. Jalvandi, M. White, Y. Gao, Y. B. Truong, R. Padhye and I. L. Kyratzis, Int. J. Polym. Mater., 2017, 66, 507-513.

88 J. Hu, H. Y. Li, G. R. Williams, H. H. Yang, L. Tao and L. M. Zhu, J. Pharm. Sci., 2017, 105, 1104-1112.

89 S. O. L. De Souza, M. C. A. Guerra, L. G. D. Heneine, C. R. De Oliveira, A. D. S. Cunha Junior, S. L. Fialho and R. L. Oréfice, J. Mater. Sci.: Mater. Med., 2018, 29, 173-183.

90 S. Iqbal, M. H. Rashid, A. S. Arbab and M. Khan, J. Biomed. Nanotechnol., 2017, 13, 355-366.

91 Y. F. Sun, H. L. Shan, J. X. Wang, X. Q. Wang, X. Y. Yang, J. X. Ding and J. Biomed, Nanotechnology, 2019, 15, 939-950.
92 T. P. Lei, X. Z. Lu and F. Yang, AIP Adv., 2015, 5, 041301041306.

93 S. A. Theron, A. L. Yarin, E. Zussman and E. Kroll, Polymer, 2005, 46, 2889-2899.

94 S. P. Fang, P. Jao, D. E. Senior, K. T. Kim and Y. K. Yoon, Micro Nano Lett., 2017, 5, 10-18.

95 K. Morikawa, A. Vashisth, C. J. Grimme, M. J. Green and M. Naraghi, Macromol. Mater. Eng., 2018, 1-9.

96 D. Liu, S. Liu, X. Jing, X. Li, W. Li and Y. Huang, Biomaterials, 2012, 33, 4362-4369.

97 Q. Q. Yu, Y. M. Han, X. C. Wang, C. Qin, D. Zhai, Z. F. Yi, J. Chang, Y. Xiao and C. T. Wu, ACS Nano, 2018, 12, 26952707.

98 R. Ramirez-Agudelo, K. Scheuermann, A. Gala-Garcia, A. P. F. Monteiro, A. D. Pinzon-Garcia, M. E. Cortes and R. D. Sinisterra, Mater. Sci. Eng., C, 2018, 83, 25-34.

99 J. N. Li, W. G. Xu, D. Li, T. J. Liu, Y. S. Zhang, J. X. Ding and X. S. Chen, ACS Nano, 2018, 12, 6685-6699.

100 Y. Yuan, K. Choi, S. O. Choi and J. Kim, RSC Adv., 2018, 8, 19791-19803.

101 I. Bonadies, L. Maglione, V. Ambrogi, J. D. Paccez, L. F. Zerbini, L. F. Rochae Silva and C. Carfagna, Eur. Polym. J., 2017, 89, 211-220.

102 B. Wang, H. Li, Q. Yao, Y. Zhang, X. Zhu, T. Xia and S. Ni, Pharmacotherapy, 2016, 83, 1345-1352.

103 L. Ma, G. Yang, N. Wang, P. Zhang, F. Guo and J. Meng, Adv. Healthcare Mater., 2015, 4, 838-843.

104 T. Potrc, S. Baumgartner, R. Roskar, O. Planinsek, Z. Lavric, J. Kristl and P. Kocbek, Eur. J. Pharm. Sci., 2015, 75, 101113.

105 M. F. Canbolat, A. Celebioglu and T. Uyar, Colloids Surf., B, 2014, 115, 15-21.

106 A. O. Basar, S. Castro, S. Torres-Giner, J. M. Lagaron and H. Turkoglu Sasmazel, Mater. Sci. Eng., C, 2017, 81, 459468.

107 M. M. Castillo-Ortega, A. G. Montaño-Figueroa, D. E. Rodríguez-Félix, G. T. Munive and P. J. HerreraFranco, Mater. Lett., 2012, 76, 250-254.

108 G. Yang, J. Wang, L. Li, S. Ding and S. Zhou, Macromol. Biosci., 2014, 14, 965-976.

109 S. Zupancic, L. Preem, J. Kristl, M. Putrins, T. Tenson, P. Kocbek and K. Kogermann, Eur. J. Pharm. Sci., 2018, 122, 347-358.

110 S. Chen, L. Ge, A. Mueller, M. A. Carlson, M. J. Teusink, F. D. Shuler and J. Xie, Nanomedicine, 2017, 13, 1435-1445. 111 D. De Cassan, S. Sydow, N. Schmidt, P. Behrens, Y. Roger, A. Hoffmann and H. Menzel, Colloids Surf., B, 2018, 163, 309-320.

112 D. Han, S. Sherman, S. Filocamo and A. J. Steckl, Acta Biomater., 2017, 53, 242-249.

113 M. E. Wright, I. C. Parrag, M. Yang and J. P. Santerre, J. Controlled Release, 2017, 250, 107-115.

114 J. J. Xue, Y. Z. Niu, M. Gong, R. Shi, D. F. Chen, L. Q. Zhang and Y. R. Lvov, ACS Nano, 2015, 9, 1600-1612.

115 L. Martinez-Ortega, A. Mira, A. Fernandez-Carvajal, C. R. Mateo, R. Mallavia and A. Falco, Pharmaceutics, 2019, 11, 14-27. 
116 A. Haider, K. C. Gupta and I. K. Kang, BioMed Res. Int., 2014, 2014, 1-10.

117 M. G. Lancina, R. K. Shankar and H. Yang, J. Biomed. Mater. Res., Part A, 2017, 105, 1252-1259.

118 Y. Zhu, M. Pyda and P. Cebe, J. Appl. Polym. Sci., 2017, 134, 1-9.

119 J. Chen, H. Pan, Y. Yang, S. Xiong, H. Duan, X. Yang and W. Pan, Int. J. Pharm., 2018, 547, 303-314.

120 G. Z. Yang, J. J. Li, D. G. Yu, M. F. He, J. H. Yang and G. R. Williams, Acta Biomater., 2017, 53, 233-241.

121 L. Zhu, J. Dai, L. Chen, J. Chen, H. Na and J. Zhu, J. Mater. Sci., 2016, 52, 2473-2483.

122 F. Croisier, G. Atanasova, Y. Poumay and C. Jerome, Adv. Healthcare Mater., 2014, 3, 2032-2039.

123 W. Gao, L. Sun, X. Fu, Z. Lin, W. Xie, W. Zhang, F. Zhao and X. Zhen, J. Mater. Chem. B, 2018, 6, 277-288.

124 R. Sarkar, A. Ghosh, A. Barui and P. Datta, J. Mater. Sci.: Mater. Med., 2018, 29, 1-16.

125 X. Zhou, H. Wang, J. Zhang, X. Li, Y. Wu, Y. Wei and Q. Zhao, Acta Biomater., 2017, 54, 128-137.

126 N. Mahmoudi, N. Eslahi, A. Mehdipour, M. Mohammadi, M. Akbari, A. Samadikuchaksaraei and A. Simchi, J. Mater. Sci.: Mater. Med., 2017, 28, 1-13.

127 R. Li, Z. Cheng, R. Wen, X. Zhao, X. Yu, L. Sun and L. Kang, RSC Adv., 2018, 8, 15558-15566.

128 P. S. Sundaran, A. Bhaskaran, S. T. Alex, T. Prasad, V. H. Haritha, Y. Anie and P. R. Anil Kumar, J. Mater. Sci.: Mater. Med., 2017, 28, 88-97.

129 S. Hinderer, M. Schesny, A. Bayrak, B. Ibold, M. Hampel, T. Walles and K. Schenke-Layland, Biomaterials, 2012, 33, 5259-5266.

130 B. L. Farrugia, T. D. Brown, Z. Upton, D. W. Hutmacher, P. D. Dalton and T. R. Dargaville, Biofabrication, 2013, 5, 1-11.

131 K. E. Kador, R. B. Montero, P. Venugopalan, J. Hertz, A. N. Zindell, D. A. Valenzuela and J. L. Goldberg, Biomaterials, 2013, 34, 4242-4250.
132 C. Vaquette, W. Fan, Y. Xiao, S. Hamlet, D. W. Hutmacher and S. Ivanovski, Biomaterials, 2012, 33, 5560-5573.

133 Y. W. Xi, J. Ge, Y. Guo, B. Lei and P. X. Ma, ACS Nano, 2018, 12, 10772-10784.

134 B. Luo, L. Tian, N. Chen, S. Ramakrishna, N. Thakor and I. H. Yang, Biomater. Sci., 2018, 6, 3262-3272.

135 Y. Wang, W. Cui, J. Chou, S. Wen, Y. Sun and H. Zhang, Colloids Surf., B, 2018, 172, 90-97.

136 X. Jing, H. Y. Mi, X. C. Wang, X. F. Peng and L. S. Turng, ACS Appl. Mater. Interfaces, 2015, 7, 6955-6965.

137 S. Mirzaei, A. Karkhaneh, M. Soleimani, A. Ardeshirylajimi, H. Seyyed Zonouzi and H. Hanaee-Ahvaz, J. Biomed. Mater. Res., Part A, 2017, 105, 2461-2474.

138 J. F. Piai, M. A. Da Silva, A. Martins, A. B. Torres, S. Faria, R. L. Reis and N. M. Neves, Appl. Surf. Sci., 2017, 403, 112-125.

139 E. Basturk, S. Demir, O. Danis and M. V. Kahraman, J. Appl. Polym. Sci., 2013, 127, 349-355.

140 M. Sarathi, N. Doraiswamy and G. Pennathur, Prep. Biochem. Biotechnol., 2019, 49, 695-703.

141 W. J. Cloete, S. Hayward, P. Swart and B. Klumperman, Molecules, 2019, 24, 508-519.

142 C. Isik, G. Arabaci, Y. I. Dogac, I. Deveci and M. Teke, Mater. Sci. Eng., C, 2019, 99, 1226-1235.

143 J. Li, X. Chen, D. Xu and K. Pan, Ecotoxicol. Environ. Saf., 2019, 170, 716-721.

144 S. Haghju, M. R. Bari and M. A. Khaled-Abad, Carbohydr. Polym., 2018, 200, 137-143.

145 J. P. D. Santos, E. D. R. Zavareze, A. R. G. Dias and N. L. Vanier, Int. J. Biol. Macromol., 2018, 118, 1676-1684.

146 P. Bosiger, G. Tegl, I. M. T. Richard, L. L. Gat, L. Huber, V. Stagl, A. Mensah, G. M. Guebitz, R. M. Rossi and G. Fortunato, Carbohydr. Polym., 2018, 181, 551-559.

147 W. J. Huang, Y. F. Zhan, X. W. Shi, J. J. Chen, H. B. Deng and Y. M. Du, Int. J. Biol. Macromol., 2017, 98, 630-636.

148 M. F. Canbolat, H. B. Savas and F. Gultkin, Anal. Biochem., 2017, 528, 13-18. 